\title{
CORRELAÇÃO ENTRE ATUAÇÃO DE GERENTES DE S. I. E ASPECTOS GERENCIAIS CONSIDERADOS IMPORTANTES
}

\section{CORRELATION BETWEEN IS MANAGEMENT ACTIVITIES AND ADMINISTRATION ASPECTS CONSIDERED IMPORTANT}

\author{
Silas Marques de OLIVEIRA*
}

RESUMO

\begin{abstract}
Pesquisas já realizadas indicam que os gerentes de unidades de informação exercem uma gama variada de atividades gerenciais além das tradicionahnente conhecidas e esboçadas em livros textos. Estas atividades possuem importância relativa para o sucesso do trabalho gerencial, são realizadas com freqüencia diferenciadas e algumas são consideradas como sendo mais fáceis de serem executadas que outras. Esta pesquisa objetiva identificar qual a relação que existe entre as atividades consideradas mais relevantes e alguns fatores inerentes ao ambiente e estrutura da unidade de informação bem como a experiência administrativa já adquirida pelos gerentes destas unidades. Os dados são analisados tendo em vista sugestões para uma formação acadêmica mais adequada dos profissionais da informação.
\end{abstract}

Palavras-chave: Gerência de Unidades de Informação; Formação Acadêmica de Profissionais da Informação.

\section{ABSTRACT}

Research has indicated that directors of information units perform a varied array of administrative activities beyond the traditional ones and presented in text books. These activities have relative importance to the success of the managerial work they are performed with different frequency and some are considered as being more difficult than others to be accomplished. This investigation identifies the relationship between the activities considered as more relevant and factors inherent to information units environment and structure as well as the managerial experience of these units directors. The data is analyzed taking in consideration suggestions for an academic instruction adequate to information professionals.

Key-words: Information unit management;

\section{INTRODUÇÃO}

Questões cada vez mais complexas estão se apresentando ao ambiente informacional: custos, eficácia e eficiência organizacional; coleções virtuais; acesso eletrônico; qualidade dos serviços; disponibilidade de novas tecnologias de informação; liderança das unidades de informação no papel

(*) Professor Titular da Pontifícia Universidade Católica de Campinas - Curso de Pós-Graduação em Biblioteconomia

Praça Imaculada 105, Santa Odila - 13045-901 Campinas, SP - E-mail: silasmarques@acad.puccamp.br 
de oferecer acesso e transferir informação, dentre outros.

A verdade é que dirigir uma unidade de informação, hoje, não é a mesma tarefa de 20 anos atrás. Novas tecnologias de informação, sistemas de informação eletrônicos, a Internet e questões de acesso têm tornado o ambiente de transferência de informação mais complexo.

O aumento dos preços dos periódicos e bases de dados, junto com o enorme volume de informação disponível, tem causado grandes problemas econômicos, obrigando os dirigentes a debruçarem com maior afinco no processo decisório envolvendo situações críticas de compatibilidade e sobrevivência das unidades de informação.

Expectativas quanto à liderança, políticas externas, demanda por responsabilidade, a introdução de novas tecnologias, e a necessidade veemente por um sólido programa de marketing estratégico e relações públicas, tornaram as práticas gerenciais duas décadas atrás obsoletas e inadequadas para uma administração eficaz de unidades de informação.

Huber (1984) já indicava, mais de 10 anos atrás, que problemas para se adequar às mudanças tecnológicas em bibliotecas eram apenas reflexos de problemas similares que estavam ocorrendo na sociedade. O mundo estava entrando em uma nova idade tecnológica que iria mudar a sociedade fundamentalmente: uma era dominada por computadores e sistemas de comunicação. A mudança é tanto rápida quanto revolucionária, e o futuro irá trazer mudanças mais rápidas e radicais ainda à reunião, processamento, e disseminação da informação em bibliotecas.

As pressões e desafios para lidar com mudança sob tais condições têm levado as organizações a procurar novos e melhores métodos de organização e administração. Enquanto alguns possam questionar a aplicabilidade dos princípios administrativos à gerência de bibliotecas, uma questão está bem clara. Instituições sem fins lucrativos estão ativamente adotando práticas administrativas.

Drucker (1989) já afirmava que todas as instituições - agências governamentais, militares, igrejas, hospitais, museus, Clube de Escoteiros - todos têm-se tornado 'management conscious'. De fato, estas instituições devem seu crescimento e impacto nos Estados Unidos em grande parte devido à adoção de, e liderança administrativa.

"Com muita razão, a administração universitária tem-se enamorado, cada vez mais, com as habilidades de negócios e administrativas: necessidade econômica e escassez de recursos. Agora, estamos encontrando CEO's do mundo acadêmico, reitores estão sendo selecionados e contratados tanto por sua capacidade administrativa quanto por suas realizações acadêmicas." (Moore, 1995, p. 13)

Ao discutir o impacto do ambiente em constante mudança na administração de bibliotecas universitárias, Moore (1995) informa que o reitor da Texas Tech University, o Dr. Robert Lawless, ex vice-presidente da Southwest Airlines, foi contratado devido à sua experiência empresarial e por sua habilidade em lidar com circunstâncias econômicas austeras, e enfatiza que o diretor da biblioteca universitária precisa ousar seguir os passos do reitor. Assim como a universidade segue uma orientação empresarial, desenvolvendo estratégias competitivas para competir com outras fontes de treinamento e educação, e desenvolver programas e projetos mais relevantes para atrair novos 'clientes', a biblioteca também deve se adequar ao impacto do ambiente em mudança, e se tornar mais 'business minded'.

Para convencer a administração superior a providenciar mais verbas para expansão e mudança, é necessário aplicar os princípios administrativos à administração da biblioteca.

\section{NECESSIDADE E IMPORTÂNCIA DO PREPARO GERENCIAL}

Treinamento em habilidades de tecnologia informacional é uma necessidade significativa, contínua. No entanto, treinamento e desenvolvimento gerencial é indiscutivelmente uma área de maior desafio, cuja provisão tem sido percebida como sendo de extrema importância mas inadequada.

Há poucos anos, Rooks (1994, p. 58) enfatizou esta importância, destacando que "para ser bem sucedido, os diretores de bibliotecas devem possuir um amor e compreensão da palavra 'impressa'. No entanto, devem também possuir habilidades de um gerente de negócios eficaz e capaz."

O reconhecimento da necessidade e da importância da aplicação de processos e teorias administrativas no ambiente biblioteconômico não é novo. McAnally e Downs (1973, p. 14), um quarto de século atrás, já percebiam que o "diretor...trabalha em condições de constante mudança, pressões intensas e grande complexidade. Estes fatores são de importância cruciais para o diretor pessoalmente, exigindo dele as mais elevadas habilidades administrativas..."

Alguns autores, além de confirmar este posicionamento, tentam esclarecer, ou pelo menos, 
oferecer sugestões quanto às causas ou barreiras enfrentadas por diretores de bibliotecas que os impedem de aplicar técnicas administrativas. Line (1991, p. 103) afirma que "uma exigência básica é que bibliotecários tomem conhecimento das tendências administrativas. Ainda pensam muito em termos das tarefas que necessitam ser executadas e muito pouco em termos da administração que é necessária para que tudo seja realizado eficientemente."

Um estudo realizado por Johnson (1991), financiado pela Library and Information Serivice Committee for Scotland, analisando a provisão e necessidade de desenvolvimento gerencial, também revelou que a maioria dos diretores investigados igualmente percebiam esta necessidade como sendo da mais elevada prioridade.

Safford (1988, p. 20) destaca a importância das tarefas administrativas e enfatiza que "mesmo nas bibliotecas com um profissional apenas, uma parte significativa do tempo do diretor deve ser devotado às responsabilidades gerenciais."

Estudando este tipo de biblioteca, Pitt (1994) identificou o perfil de 67 diretores, destas chamadas "One-Person-Library". Eles indicaram "tarefas administrativas" como sendo a primeira na lista, em termos de funções que realizam regularmente.

As habilidades administrativas também são consideradas importantes para os profissionais que ambicionam trabalhar em ambientes que processam e fornecem acesso à informação comercial e empresarial. De acordo com James (1989, pp. 355, 356), "habilidades gerenciais consideráveis precisam ser demonstradas pelos 'business information professionals' para selecionar, adquirir e usar tais informações de uma forma custo eficaz."

Este mesmo autor conclama as instituições de ensino, na área de informação, para mudar seus programas, e incluir habilidades gerenciais, porque "esta é a única forma para compreender, competir e ser bem sucedido no ambiente de negócios atuais e futuro..." e envia um recado aos estudantes de ciência da informação que intencionam trabalhar neste ramo, enfatizando que estes "precisam estar conscientes do conteúdo gerencial de seu trabalho... o desenvolvimento das habilidades gerenciais... irá definitivamente expandir os horizontes... alargar sua função e ajudá-los a assumirem seu lugar e serem reconhecidos como gerentes chaves em suas organizações" (James, 1989).

Se por um lado a profissão reconhece a necessidade não só da aplicação de técnicas e conhecimentos administrativos em bibliotecas, ela também vem, ao longo do tempo, denunciando a inadequação do programa acadêmico dos profissionais para assumirem funções gerenciais de suas bibliotecas. A despeito da atenção dada ao assunto, tanto na literatura da área, quanto através de iniciativas práticas, um tema constante dos autores é que os bibliotecários não possuem as habilidades e técnicas necessárias para realizarem um trabalho gerencial de nível elevado e eficaz, e que é necessário haver maior exposição e experiência com questões administrativas por parte dos gerentes potenciais e atuais.

De acordo com Peel (1989), a profissão não está treinando adequadamente os gerentes de bibliotecas para exercerem esta função. Ele cita dois relatórios Britânicos que confirmam sua posição com muita clareza. O de Constable e McCormick, "The Making of British Managers" e o de Handy, "The Making of Managers". Os resultados destes relatórios, conforme Peel, não têm sido contestados e nem desafiados e têm sido a base para muitas providências desde que foram publicados.

Fieldman (1993) corretamente aponta que a administração de bibliotecas está se tornando cada vez mais complexa, tanto política quanto tecnicamente, exigindo alto nível de habilidades gerenciais. Seu relatório destaca que treinamento gerencial para serviços de informação/bibliotecas é subdesenvolvido e que a provisão para esta área tem sido pobre.

Quase 20 anos atrás o Library Association Working Party on Post-Qualification Training identificou uma necessidade para um extensivo treinamento em habilidades gerenciais, e conseguiu recursos do British Library Research and Development Department para investigar esta situação.

Dez anos mais tarde, outro estudo confirmou não só as conclusões daquele estudo como também de outros que identificaram a necessidade de treinamento gerencial como sendo uma preocupação prioritária (Anderson, p. 1997).

Brindley (1987), em seu discurso durante o 1987 Aslib Annual Conference, descreveu um nítido paralelo entre os desafios enfrentados pela profissão e os enfrentados no mundo comercial e industrial - notadamente, gerência financeira e planejamento estratégico. Neste discurso, ele argumenta que os padrões da época concernentes a treinamento gerencial não eram suficientes para satisfazer necessidades identificadas na área de desenvolvimento gerencial, na qual a interação entre teoria e prática é uma parte essencial ao crescimento e desenvolvimento de competência.

Line e Robertson (1989) destacam as limitações dos cursos regulares com relação ao preparo de gerentes eficazes. Sugerem um ponto de vista mais holístico para 
o desenvolvimento de pessoal, reconhecendo que técnicas gerenciais novas ou diferentes podem ser aplicadas com sucesso apenas num ambiente receptivo e participativo.

\section{FUNÇÕES GERENCIAIS}

Os papéis dos diretores de bibliotecas, independente de época, são caracterizados por circunstâncias sensíveis ao tempo, tais como, questões de nível de qualificação de pessoal esperado, demandas organizacionais e operacionais, imposições e ou restrições econômicas, necessidades de ampliação e reestruturação, desenvolvimento tecnológico, etc. Portanto, não é de se admirar que Rooks (1994, p. 57) tenha afirmado que "o sucesso do diretor de biblioteca, hoje, depende muito mais de sua habilidade gerencial que de um conhecimento aprofundado de biblioteconomia", tendo, justamente em vista, o ambiente em constante mudança que causa um forte e acentuado impacto em todo o processo de aquisição e acesso à informação.

A área de Biblioteconomia e Ciência da Informação, representada por seus pesquisadores, vem sentindo o impacto destas mudanças na administração de unidades de informação de todos os tipos já há algum tempo. Holley (1972), pox exemplo, há quase 25 anos atrás, já havia detectado mudanças na organização e administração de bibliotecas universitárias urbanas.

Um ano mais tarde, McAnally e Downs (1973) produziram um trabalho clássico sobre as pressões que afetam as funções dos diretores deste mesmo tipo de bibliotecas.

Lee (1977) foi um dos primeiros a examinar as pressões nos diretores de bibliotecas universitárias bem como os efeitos que estas pressões exerciam em suas funções gerenciais. Poucos anos depois, Metz (1979) analisou dados descritivos para compreender os papéis dos diretores, especificamente, os relacionamentos externos. Ele concluiu que questões internas da biblioteca exigiam mais tempo e energia que as questões externas.

No entanto, o estudo de Baughman (1980), que investigou os papéis dos diretores de bibliotecas metropolitanas, demonstrou que cada vez mais tempo era necessário para lidar com questões externas às operações do dia-a-dia dentro das bibliotecas.

Em realidade, as bibliotecas estavam apenas no limiar de uma série, de períodos de transição que continua até hoje, cada um com duração menor que o anterior.
Mas mais cinco anos passariam até que muitos pesquisadores começassem a analisar de forma séria e sistemática as mudanças dos papéis dos gerentes de grandes bibliotecas causadas por mudanças nas organizações, gerência, tecnologia, custos e políticas externas.

Moskowitz (1986) e Mech (1989 e 1990) usaram o modelo de funções de Mintzberg em três estudos diferentes. Concordando com Metz (1979), mas discordando das observações realizadas anteriormente por Baughman (1980), aqueles dois autores concluíram que os diretores de bibliotecas, tanto públicas quanto universitárias, estavam enfatizando as funções gerenciais internas sobre as questões ambientais externas.

O trabalho de Euster (1987) providencia um importante novo modelo de papel do diretor. O modelo define os papéis dos diretores de bibliotecas universitárias em termos de influenciar tanto a organização interna da biblioteca quanto o ambiente externo.

Um ano antes, Lewis (1986, p. 234) acentuou a necessidade do diretor de bibliotecas analisar sua estrutura organizacional tendo em vistas questões de compatibilidade com as "novas" exigências do ambiente e mercado como uma função importante do diretor.Ele afirmava que "a estrutura organizacional de bibliotecas universitárias não são apropriadas para exercer o papel que é esperado das mesmas." Neste trabalho, o autor discorre sobre os diversos conceitos e modelos de estruturas, responsabilizando o diretor da biblioteca para encontrar e implantar a mais eficiente.

Na tentativa de apoiar sua posição, o autor cita Kanter (1983) : "Se as bibliotecas universitárias desejam ser inovadoras no sentido de usar criativamente as novas tecnologias, elas precisam primeiro ser inovadoras quanto às suas estruturas organizacionais."

Lewis (1986) preocupa-se também com o impacto que o nível e qualidade de pessoal exerce na eficiência das operações da biblioteca. Conforme aquele autor, "a primeira exigência para uma biblioteca universitária eficaz é a capacidade de recrutar e manter pessoal competente e motivado. Como Battin (1984:22) tem dito, "a qualidade do pessoal da biblioteca durante a próxima década será mais importante para a sociedade futura e vitalidade da universidade do que a qualidade do pessoal de ensino e administrativo."

A partir do final da década de 1980, com exceção de alguns que concentraram suas pesquisas em tópicos bem específicos da administração, a maioria dos autores que investigaram e analisaram as diferentes funções administrativas dos diretores de bibliotecas destacaram 
uma plêiade de habilidades e conhecimentos gerenciais que estes deveriam possuir para executar com competência o papel de diretor.

Assim, Baker, (1988) em sua palestra por ocasião da Education Librarians Group/Librarians of Institutes and Schools of Education Annual Study Conference, em 1988, fortemente recomendou a adoção de técnicas gerenciais por bibliotecários. Técnicas tais como planejamento estratégico e marketing, bem como habilidades incluindo aconselhamento e acompanhamento.

Em um estudo posterior, Peel (1989, p. 288) enfatiza que o gerente de bibliotecas deveria ser capaz de "delegar, motivar, coordenar, monitorar e controlar (supervisionar) o trabalho dos outros, disciplinar quando necessário, desenvolver a equipe e os indivíduos, desenvolver um orçamento e controlar as finanças... Deve ter habilidades em resolução de problemas, tomada de decisão, planejamento, organização, lidar com stress, determinar prioridades, e comunicar." Como parte da comunicação, o autor menciona: leitura dinâmica, dirigir-se a grupos, escrever cartas e relatórios, liderar reuniões e lidar com a mídia.

Muitas vezes esta imensa gama de habilidades é ignorada. Ou é presumido que o recém encarregado de gerenciar já a possui, ou de alguma forma, como um passo de mágica, o indivíduo irá adquiri-la assim que for necessário. Os novos gerentes correm o perigo de afastarem-se de suas responsabilidades gerenciais, de comando, e submergirem-se nas atividades de rotina que já dominam. O desastre é inevitável - uma administração inadequada de sua própria biblioteca.

Ainda neste mesmo ano, James (1989, pp. 356, 361) destacou nove áreas da administração, ou habilidades chaves que os gerentes que lidam com informação para negócios precisam dominar. São elas: "compreensão da estrutura organizacional; orçamento e contabilidade; pessoal - seleção e desenvolvimento; negociação, planejamento, gerência de dados internos; gerência de tempo; comunicação; e marketing."

Conforme o autor, estas habilidades alargarão definitivamente os horizontes e garantirão um lugar ao sol na organização entre os gerentes de outras áreas. Ele acentua que a única forma destes profissionais assumirem seus lugares de direito dentre os gerentes da organização altamente reconhecidos e recompensados é comportarem-se e agirem como gerentes eficazes primeiro, e, depois, como profissionais da informação para negócios.

Um trabalho interessante é apresentado por Martin (1989) ao analisar e discutir o impacto que a absorção de uma variedade de tecnologias pelas bibliotecas vai ter no processo gerencial. O impacto destas se refletirá no orçamento, na estrutura organizacional, no comportamento do pessoal, no planejamento, e exigirá uma ampla participação de todos os membros da organização, ou seja, uma administração participativa.

Marchant e England (1989, p. 470) também compartilham desta opinião, e defendem que a forma mais eficaz de gerenciar uma biblioteca na era da informatização é através da utilização de uma administração participativa. Assinalam que "a busca por sistemas administrativos mais eficazes, dinâmicos, flexíveis e competitivos estão levando os gerentes, trabalhadores e acadêmicos a uma visão renovada do valor da administração participativa, uma teoria introduzida a mais de duas décadas..."

Para estes autores, os métodos de administração participativos tem sido desenvolvidos e testados suficientemente para considerá-lo viável. O que é necessário ser discutido, no entanto, é como gerenciar este modelo admmistrativo para alcançar os resultados esperados.

Embora a ênfase do trabalho de Marchant e England (1989) seja demonstrar a importância da administração participativa no contex to informacional, eles também mencionam outras habilidades administrativas que influenciarão no sucesso da administração de bibliotecas, como: manter os trabalhadores altamente motivados, manter a pirâmide da estrutura achatada, ou seja, horizontalizada; e adotar equipes de trabalhadores para controlar a informação e compartilhá-la no processo de tomada de decisão.

Para manter os trabalhadores motivados e satisfeitos, Birdstall (1990:209), em um trabalho singular, defende que os administradores de bibliotecas precisam aprender a responder às necessidades de experiências de trabalho gratificante de seu pessoal, e alcançar um equilíbrio entre estas e as metas da organização. Afirma que "é esperado dos gerentes...em todos os níveis hierárquicos, preencher vários papéis: gerência burocrática eficiente, advogado bem sucedido para aumentar as verbas, político astuto, planejador visionário, líder inspirador. Existe, no entanto, um outro papel que é raramente reconhecido, embora com freqüência seja executado diariamente. Ao realizar o papel de terapeuta, os gerentes de bibliotecas ajudam assegurar que o pessoal alcance auto-gratificação através de seus trabalhos."

É evidente que isto requer que os gerentes providenciem meios de satisfação psicológica através dos quais os funcionários possam alcançar maior auto-realização. O nível de sentimento de bem-estar 
do pessoal tornou-se uma medida de eficácia gerencial.

A partir dos anos 90 percebe-se uma maior preocupação por parte dos pesquisadores e intelectuais da área que, em realidade, é uma mudança de enfoque com relação à maioria dos trabalhos anteriores. Nesta nova era da informação e tecnologia informacional, estes autores se debruçam sobre o meio ambiente na tentativa de identificar como as tendências da atualidade (principalmente tecnológicas) afetam as práticas gerenciais dos diretores de unidades de informação.

Conforme Line (1991, p. 97), "a abrangência de habilidades necessárias" [ou seja, habilidades dos diretores de bibliotecas] "aumentou, mas muitas destas não são biblioteconômicas; elas são computação, desenvolvimento de sistemas e marketing e assim por diante"... "estruturas mais horizontais... ajudariam a realizar as mudanças necessárias... maior delegação pode ser iniciada a qualquer momento. Planejamento estratégico pode ser uma excelente forma para o pessoal aprender novas habilidades e atitudes e lidar com mudança."

Aquele trabalho discute diversas áreas da administração que são consideradas como sendo habilidades necessárias para o desempenho eficaz no gerenciamento da biblioteca. São elas: gerência dos recursos humanos, incluindo treinamento e delegação de poder, estrutura organizacional, comunicação, tomada de decisão, atendimento e relacionamento com o cliente, conhecimento do mercado, marketing, e gerência de equipes. Todos estes aspectos sob a ótica do impacto da tecnologia.

Em um excelente estudo, Cottam (1994) oferece uma visão contemporânea e seletiva das funções de diretores de 30 bibliotecas de grande porte nos Estados Unidos. A pesquisa focalizou as posições atuais dos diretores e como elas contrastam com as responsabilidades de 5 e 10 anos. Para isto, os diretores responderam a seis questões, para, em síntese, indicar as funções e atividades que demandavam maior atenção, quais os fatores que determinam as prioridades do tempo deles, quais eram os papéis gerenciais internos e externos enfatizados, quais eram as funções mais apropriadas para delegação, e identifcar as atividades que realizavam por ocasião da pesquisa que eram diferentes das que realizavam 10 anos atrás.

A pesquisa demonstrou que "contato com o pessoal" seja, talvez, a principal ocupação dos diretores, ocupando um papel central e tida quase como uma regra. Descreveram esta responsabilidade de diversas formas - comunicação, desenvolvimento de times, relações com o pessoal.
A maior diferença com relação à utilização do tempo e energia tem como fonte o aumento das opressões econômicas. Os diretores, conforme o estudo, "gastam cada vez mais tempo lidando com os efeitos dos orçamentos em declínio ao reavaliar prioridades e trabalhar para complementar as verbas usuais com outras fontes de apoio financeiro" (Cottam, 1994, p. 21). Estes diretores indicaram que um programa de apoio externo e levantamento de recursos requer muita atenção, liderança e participação direta, sendo necessário, portanto, delegar mais as outras responsabilidades.

Outra função "externa" que consome muito tempo dos diretores, de acordo com os resultados da pesquisa, é a chamada "relações comunitárias", ou "relações públicas". Esta atividade inclui contatos dentro do campus universitário, ou seja, com alunos, reitores, administradores, professores e etc., assim como com profissionais da área, outras instituições e etc.

As funções gerenciais que exigem mais atenção dos diretores, mencionados na pesquisa, são: comunicação; delegação; pessoal; planejamento; desenvolvimento de políticas e estabelecimento de prioridades; avaliação; monitoria do desenvolvimento tecnológico; administração de mudança; e administração de projetos de construção. Todos incluídos como funções "internas". As principais funções "externas" apontadas foram: consórcio e convênios; relações inter-institucionais; e relações públicas e promoção (Cottan,1994).

Os resultados da pesquisa de Cottam (1994) indicam que os papéis têm mudado nos últimos anos. Estão ocorrendo mudanças nas prioridades com relação às funções e atividades. Os papéis tradicionais gerenciais ainda existem, mas ambas circunstâncias internas e fatores ambientais externos estão levando os diretores a dedicarem mais tempo agora do que antes a questões externas ao dia-a-dia das responsabilidades operacionais e organizacionais da biblioteca.

O enfoque das questões externas inclui planejamento estratégico correlacionado com tendências ambientais amplas de cooperação inter-institucional, comunicação entre consórcios e conveniados, levantamento de recursos e liderança em associações profissionais.

Os diretores dedicam mais tempo hoje que 5 a 10 anos atrás respondendo e planejando em função das mudanças sociais (e.g. tendências à aprendizagem contínua, pressões econômicas, mudanças tecnológicas, aumento da cobrança pública) e menos tempo às questões localizadas especificamente nas bibliotecas. Ou seja, tentam visionar, desenvolver e oferecer respostas estratégicas ao ambiente externo, ensinando e 
influenciando o pessoal com respeito a valores, propósito e direção que a biblioteca precisa tomar - comunicando, delegando e construindo confiança.

Ao analisar os papéis dos diretores do setor de referência, Nofsinger e Bosch $(1994: 87,88)$ indicam que estes papéis estão sendo redefinidos gradualmente, e que "o aumento da complexidade dos serviços de referência tem causado o surgimento de necessidades para novos treinamentos, conhecimentos e habilidades."

Dos três papéis mencionados pelos autores como sendo primários, dois dizem respeito diretamente à administração. São eles: gerência de pessoal e liderança e planejamento antecipado para mudanças no futuro.

Os diretores precisam, portanto, independente dos setores que gerenciam, coordenar o funcionamento das rotinas do dia-a-dia, mcluindo o trabalho do pessoal, definindo os horários dos serviços, monitorando os gastos, alocando recursos para projetos e desenvolvimentos de serviços, produtos e programas específicos. Precisam monitorar comportamentos e atitudes do pessoal.

Em adição, supervisão geralmente inclui a coordenação de coleta de dados, a elaboração de manuais de procedimentos, o esclarecimento de descrição do trabalho e a apresentação de relatórios sobre as operações da unidade.

Outras funções administrativas mencionadas pelos autores acima citados são: treinamento e coordenação, comunicação, avaliação de desempenho, administração de conflito e stress, liderança e planejamento estratégico, sendo esta última a ênfase dada por Corrall (1994a), além de atendimento ao cliente e gerenciamento de qualidade total.

Em um outro trabalho, Corrall (1994b, p. 209) conclui que "diretores de bibliotecas devem ser capazes de aplicar habilidades que são apropriadas aos outros diretores envolvidos com finanças, estratégias e administração de pessoal." Esta autora argumenta que existe urgência por parte das Instituições para desenvolverem estratégias informacionais integradas, o que requer uma cooperação mais acentuada entre a biblioteca e as funções de ensino e pesquisa.

As principais áreas de preocupação, anotadas por Pitts (1994) ao identificar o perfil de 67 diretores de bibliotecas com apenas 1 profissional, são: automação, administração do tempo, orçamento, pessoal. Outras áreas mencionadas por aqueles diretores foram planejamento e reforma de prédio, além de comunicação e organização.

Ao analisar o impacto do ambiente na administração de bibliotecas, Moore (1995:17) afirma que "a era da informação requer que os administradores de bibliotecas reúnam suas equipes, e se concentrem imediatamente em responder à pergunta: em que negócio estamos? em que negócio devemos estar?" Este processo inclui, naturalmente, diagnosticar o ambiente periodicamente para identificar ameaças e oportunidades e a aplicação de planejamento estratégico.

Ao lidar com este processo, a tomada de decisão se torna mais complexa, pois os administradores precisarão lidar com o fato de que a missão tradicional da biblioteca tem mudado e sua meta anterior rapidamente se toma inviável.

Para ter sucesso neste contexto, Moore (1995) sugere que algumas habilidades gerenciais são cruciais, tais como: saber contratar pessoal altamente qualifcado; ser sensível às necessidades dos empregados; trabalhar em equipe; aplicar os princípios de qualidade total; conhecer técnicas de atendimento e relacionamento com os clientes; proporcionar educação continuada e treinamento; planejar marketing estratégico; e promover alianças estratégicas com outras instituições.

Moore (1995, p. 29) sugere algumas áreas específicas que poderiam estar sendo beneficiadas com tais alianças, tais como "desenvolvimento de novos sistemas de acesso à informação, inteligência artificial, bibliotecas virtuais, sistemas especialistas e projetos de engenharia do conhecimento." As bibliotecas precisam, portanto, aprender a ter um novo e diferente relacionamento com sua clientela e com o ambiente ao seu redor para tirar melhor proveito do contexto informacional em que vivemos hoje.

Preocupada com o tipo de liderança necessária para enfrentar o contexto que o futuro proporcionará, Taylor (1995) sugere as qualidades de liderança que devemos buscar nos diretores de bibliotecas que ajudarão a levar as instituições para o futuro gerenciando serviços de informação no século 21 . Ela expõe que este líder precisa possuir coragem para abraçar mudança e desafios, talento para desenvolvimento de equipes, ser capaz de liderar em um ambiente ambíguo e possuir uma visão de futuro.

Taylor (1995, p. 15) afirma que esta "visão é crítica para se saber onde se quer ir, mas o que poderá ser mais importante é a habilidade de colocar esta visão no contex to dos valores comunitários, a competência de articular a visão ao pessoal, administradores e usuários. Ter uma visão possui pouco valor se ela não for traduzida em planos de ações específicos que resultem na transferência de serviços àqueles que buscam informação."

Em um artigo mais recente, Shaughnessy (1996, p. 48) concorda e defende a necessidade de 
estabelecer esta visão. Para ele, uma das novas funções do diretor da biblioteca é "criar um novo modelo mental da organização, ajudando-a desenvolver uma nova e poderosa visão do futuro."

Webb (1997), em seu editorial, destaca diversas funções que os gerentes de informação devem assumir nos anos 90, baseada em pesquisas realizadas por diferentes instituições governamentais e particulares. Após uma análise e discussão detalhada, a autora recomenda que os gerentes de informação precisam ter habilidades em comunicação, treinamento, recrutamento, liderança de equipes, liderança e solução de problemas.

Ao reexaminar o papel do bibliotecário na "era da informação", Gessesse (1997) afirma que estes profissionais precisam assumir o papel de líderes em preparar a comunidade usuária de informação para esta "nova" era e assegurar o acesso à informação para um segmento maior desta comunidade. Para desenvolver este papel de forma eficaz, este profissional terá que aplicar técnicas de reengenharia para reestruturar seus serviços, trabalhando em equipes, utilizando um enfoque centrado no cliente, treinar seu pessoal para desenvolver este novo papel, e ter muito cuidado com os custos de todas as operações.

Nesta mesma linha de raciocínio, Woodsworth (1997) indica que funções como: avaliação de multimídia, software, hardware, redes, treinamento de usuários, liderar mudanças, comunicação, desenvolver novos serviços bem como políticas de informação e de atendimento ao cliente e desenvolver programas de educação continuada para seu pessoal são as competências que os gerentes de informação precisam ter no ambiente tecnológico. De acordo com Hisle (1997), todas estas habilidades são importantes mas não se deve esquecer que os valores tradicionais ainda são relevantes na era da informação eletrônica.

Outros dois trabalhos, um publicado em 1997 e o outro em 1998, fornecem cenários dos novos horizontes tecnológicos e oportunidades trazidas para o âmbito da Biblioteconomia e Ciência da Informação. Hyams (1997) revela que os gerentes de informação devem identificar questões estratégicas, reconhecer e aprimorar as competências de seu pessoal através de programas de treinamento, e principalmente saber organizar e desenvolver serviços e trabalhar em equipes multidisciplinares para poder fazer frente às necessidades de sua clientela bem como das constantes mudanças que ocorrem atualmente no ambiente informacional.

Garrod (1998) indica que além das habilidades necessárias para lidar com a tecnologia informacional (conhecimento de html, auxílio aos usuários para lidar com os recursos da tecnologia informacional, uso da variada gama de aplicativos, etc.) treinamento e recrutamento de pessoal seriam competências essenciais aos gerentes da informação para sobreviver na era da tecnologia informacional.

Utilizando um discurso diferente, na tentativa de "esfriar" a euforia dos protagonistas da "morte" das funções tradicionais do profissional da informação com o advento da informação eletrônica, Abell (1997, p. 539) argumenta que "as habilidades tradicionais estão se tornando mais valiosas do que nunca". As habilidades que serão utilizadas para criar organizações "conhecimento intensivas" bem sucedidas são: compreensão do uso e fluxo de informação; avaliação, seleção, organização e disseminação. Todas estas habilidades sempre foram exigidas do profissional da informação bem sucedido.

Abell (1997) também descreve as novas habilidades que terão que ser empregadas neste ambiente, sendo as principais delas: a comunicação, iniciativa e marketing.

No verão de 1996, Knight-Ridder Information, Inc. e a Teltech Technical Knowledge Service concordaram em patrocinar até o ano 2000 o Programa de Liderança Executiva desenvolvido pela Special Libraries Association. O curso foi montado a partir de uma pesquisa de mercado. Para tanto, entrevistaram 23 executivos de 11 empresas. Os resultados desta pesquisa são muito oportunos tendo em vista a discussão deste trabalho. Os resultados não apenas oferecem "insight" valioso com relação às competências e habilidades esperadas dos executivos em geral, mas também dos "knowledge executives" em particular.

Após a categorização destas competências, foi identificado quais delas que o profissional da informação deveria possuir também. Assim, a pesquisa determinou que os bibliotecários e/ou profissionais da informação deveriam esmerar-se em possuir habilidades como: comunicação, promover participação em todos os níveis da organização, planejar novos serviços e produtos, compreensão prática de tecnologia informacional, liderança, criar parceiros estratégicos, e possuir habilidades inter-pessoais (Corcoran \& Jones, 1997).

Portanto, é importante conhecer não só os aspectos gerenciais que diretores e/ou gerentes de unidades de informação consideram relevantes hoje mas também a relação que existe entre estes e algumas das especificidades de sua atuação, tais como, tipo de função técnica que desenvolve, tamanho da equipe que comanda, e número de anos no cargo gerencial, ou seja, experiência. 
Estas informações poderão ser úteis para os gerentes de unidades de informação saberem, de antemão, quais são as áreas da gerência que ele/ela precisa ter embasamento com maior profundidade para exercer seu papel como gerente com maior eficácia, dependendo das outras funções que também terá que exercer bem como do tamanho da equipe que estará sob seu comando direto.

Os dados poderão revelar a necessidade de fragmentar e especializar o conteúdo de disciplinas e de iniciativas de treinamento na área de administração em escolas de Biblioteconomia e órgãos de classe da profissão bibliotecária para atender de forma mais adequada as necessidades dos alunos e profissionais já estabelecidos.

\section{OBJETIVOS}

A pesquisa teve como objetivo primordial, identificar correlações existentes entre variáveis de aspectos de trabalho e aspectos gerenciais relevantes na gerência de unidades de informação.

Os objetivos específicos que deram suporte à pesquisa, são:

(1) identificar funções auxiliares (técnicas) que gerentes de unidades de informação exercem além dos compromissos administrativos;

(2) identificar o tamanho da equipe de trabalho liderada pelos gerentes de unidades de informação;

(3) identificar o número de anos que os gerentes estão no exercício deste cargo;

(4) correlacionar funções auxiliares exercidas vs. aspectos gerenciais considerados importantes, freqüentes e difíceis;

(5) correlacionar tamanho de equipe de trabalho vs. aspectos gerenciais considerados importantes, freqüentes e difíceis;

(6) correlacionar tempo de chefia vs. aspectos gerenciais considerados importantes e difíceis;

\section{MÉTODO}

A presente pesquisa é um estudo quasi-experimental, no qual foram utilizados questionários procurando, através da análise dos resultados, um maior entendimento e percepção da relação entre diversos aspectos da gerência de unidades de informação e aspectos pessoais dos gerentes. Esta relação, indispensável para compreensão da essência desta prática gerencial, é carente de pesquisas formais na área da Ciência da Informação, embora haja inúmeros trabalhos relatados na literatura sobre a importância e necessidade dos bibliotecários conhecerem de forma mais aprofundada os fundamentos da administração, para que possam desenvolver suas obrigações de forma mais eficazes, embasados em dados cientificamente coletados.

\section{Sujeitos}

O universo da pesquisa constituiu-se de 63 diretores de unidades de informação (acima de 10.000 volumes) do estado de São Paulo, escolhidos através de amostra estratificada (30\%) por tipo de biblioteca.

\section{Material/Instrumento}

Os dados foram levantados através de um questionário dividido em duas partes. A primeira designou identificar os sujeitos (diretores de unidades de informação) quanto ao tipo de biblioteca que ele(a) gerencia (universitária, pública, escolar, especializada), ano de sua graduação, funções que exerce além das funções administrativas, formação além da de Biblioteconomia, cursos de extensão e workshops realizados na área gerencial, tamanho do corpo de pessoal sob sua responsabilidade, etc.

A segunda parte do questionário visou identificar, através de uma escala de Likert (1 a 5): a) o grau de importância que o gerente/diretor atribui a 35 aspectos gerenciais para o sucesso administrativo de sua unidade; b) a grande dificuldade que ele sente com relação a cada aspecto; c) a freqüência destes aspectos na unidade de informação (Anexo).

\section{ANÁLISE DE RESULTADOS E DISCUSSĀO}

Os resultados serão apresentados e discutidos levando-se em consideração três fatores: (1) gerentes com responsabilidades diversas; (2) tempo no cargo de gerência; e (3) número de funcionários.

\section{Responsabilidades Dos Gerentes}

O estudo identificou quatro tipos de responsabilidades dos gerentes além daquelas como 
Gerentes gerais de suas Unidades de Informação. Ou seja, responsabilidades nos Setores de Circulação, Referência, Seleção e Aquisição e Processamento Técnico. Para cada uma destas responsabilidades, identificaram-se quais dos 35 aspectos gerenciais (Anexo) arrolados foram considerados Muito Importantes, Muito Freqüentes, e Muito Difíceis de serem executados.

\section{Gerentes com Responsabilidades no Setor de Clrculação}

O aspecto Planejamento Estratégico foi indicado como sendo um aspecto de extrema relevância para estes gerentes, pois, conforme anotado, foi o único aspecto considerado como sendo de Muito destaque nos três índices investigados.

Tendo em vista melhorar a eficácia e eficiência de gerentes de Unidades de Informação que possuem responsabilidades no Setor de Circulação, os aspectos Uso de Técnicas de Organização, Tomada de Decisão, Avaliação de Serviços, Controle de Qualidade e Diagnóstico devem ser enfatizados em esforços de treinamento e desenvolvimento informais e os aspectos Planejamento Estratégico, Marketing, Administração de Stress, Comunicação e Técnicas de Dirigir Grupos devem ser enfatizados nos programas de formação básica deste profissional.

\section{Gerentes com Responsabilidades no Setor de Referência}

O aspecto Elaboração de Políticas não foi considerado como sendo relevante para os gerentes que possuem responsabilidades no Setor de Referência, pois consideraram de Pouca Importância, Pouca Dificuldade e Pouco Freqüente, embora parece-nos que o desenvolvimento de políticas seja de muita importância para quem trabalha neste setor, pois sem uma política adequada de atendimento e prestação de serviços nesta área, talvez o cerne da atividade biblioteconômica, as atividades podem ser desenvolvidas sem prioridades e limitações.

Outras atividades, tais como Determinação de Metas e Objetivos, Avaliação de Bibliotecas, Estudos de Comunidades e Elaboração de Orçamento também foram consideradas como sendo de Pouca Importância, outra vez, estranhando-nos o fato do item Estudos de Comunidades estar incluso nesta relação, pois a meta e o objetivo primordial deste Setor é o atendimento ao usuário, como já destacado, e o principal instrumento de aproximação entre a oferta da Unidade de Informação tentando compatibilizá-la às necessidades dos usuários é justamente o Estudos de Comunidade.

Considerando os resultados obtidos, os aspectos Uso de Técnicas de Organização e Avaliação de Serviços, Desenvolvimento Organizacional, Marketing, Organização e Métodos, Planejamento Estratégico, Comunicação e Seleção de Pessoal devem ser cuidadosamente enfatizados nos cursos de preparo informal. Já os aspectos Uso de Técnicas de Direção, Tomada de Decisão, Planejamento de Serviços e Liderança devem ser levados em consideração no preparo formal do profissional da informação que deverá assumir cargos de gerência com responsabilidades no Setor de Referência.

\section{Gerentes Com Responsabilidades no Setor de Seleção e Aquisição}

Vários dos gerentes que participaram da pesquisa indicaram que, além de sua função como Gerente, também dedicavam parte do tempo no Setor de Seleção e Aquisição ou desenvolviam atividades lá como parte de sua rotina de trabalho.

Os resultados apontam que, tendo em vista esforços informais de treinamento e desenvolvimento bem como programas de educação continuada, os aspectos Uso de Técnica de Organização, Uso de Técnicas de Direção, Desenvolvimento Organizacional, Avaliação de Serviços, Administração de Stress e Delegação de Poder devem ser considerados. Os aspectos Marketing, Planejamento Estratégico, Comunicação, Seleção de Pessoal e Técnicas de Dirigir Grupos devem ser enfatizados, tendo em vista profissionais gerentes de UI com responsabilidades no Setor de Seleção e Aquisição. Já os aspectos Controle de Qualidade, Organização e Métodos e Liderança devem ser levados em consideração nos cursos de preparação formal destes profissionais.

\section{Gerentes Com Responsabilidades no Setor de Processamento Técnico}

Os gerentes com responsabilidades no Setor de Processamento Técnico indicaram 20 aspectos gerenciais como sendo Muito Importantes, conforme indicado, sendo que 4 deles como sendo Muito Importantes, Muito Difíceis e Muito Freqüentes. São 
eles: Estrutura Organizacional, Resolução de Conflitos, Administração de Stress e Administração do Tempo.

Tendo em vista o conteúdo de programas de educação formais dos profssionais da informação, os aspectos Estrutura Organizacional, Resolução de Conflitos, Administração de Stress e Administração do Tempo devem ser enfatizados por serem, de acordo com este grupo de gerentes, os mais relevantes, seguidos do aspecto Tomada de Decisão. Já os cursos e esforços de educação continuada e treinamento informal devem considerar o aspecto Uso de Técnicas de Organização.

O aspecto gerencial Elaboração de Políticas foi considerado com sendo Pouco Importante, Pouco Difícil e Pouco Freqüente, sendo que o aspecto Avaliação de Bibliotecas foi tido como sendo Pouco Importante e Pouco Freqüente. Além destes dois aspectos mencionados, Determinação de Metas e Objetivos, Estudo de Comunidade e Liderança também foram tidos como sendo de Pouca Importância para este grupo de gerentes.

Embora poucos aspectos foram tidos como sendo altamente relevantes (Muito importante, Difícil e Freqüente), eles variaram de acordo com os Setores onde os gerentes também possuem responsabilidades. Apenas três aspectos coincidiram: Uso de Técnicas de Organização para Referência e Aquisição; Avaliação de Serviços para Referência e Aquisição; e Administração de Stress para Aquisição e Processamento Técnico.

Esperava-se que o aspecto Uso de Técnicas de Organização seria altamente relevante em qualquer setor de trabalho da Unidade de Informação. No entanto, ficou limitado a dois setores apenas. Sendo o Setor de Processamento Técnico um grande "gargalo" para o funcionamento eficaz de qualquer Unidade de Informação, parece-nos que Técnicas de Organização seria muito bem vinda a este Setor. No entanto, não foi tida como relevante para os gerentes investigados, nesta pesquisa, que exercem funções naquele Setor.

$\mathrm{O}$ fato dos gerentes que atuam também nos Setores de Referência e Aquisição perceberem o aspecto Avaliação de Serviços como sendo de extrema relevância parece-nos bastante coerente, pois tanto a política de Aquisição quanto o atendimento final dos usuários através do Setor de Referência irão grandemente determinar a utilidade, eficâcia e compatibilidade da "oferta" de toda organização.

Embora seja compreensível que os gerentes que atuam no Processamento Técnico destaquem a Administração de Stress, devido talvez ao acúmulo de serviço que este Setor sofre constantemente, não é tão fácil divisar o motivo deste aspecto ser tão relevante para os gerentes que também atuam no Setor de Aquisição, a não ser pela grande responsabilidade que recai sobre todos que atuam neste Setor, pois deles depende grandemente a utilidade que a Instituição terá para seus clientes.

$\mathrm{O}$ aspecto Marketing foi tido como sendo Muito Importante e Muito Difícil para os gerentes que atuam também nos Setores de Circulação, Referência e Aquisição. O aspecto Planejamento Estratégico coincidiu nos Setores de Referência e Aquisição. Comunicação nos Setores de Circulação, Referência e Aquisição. O aspecto Seleção de Pessoal nos Setores de Referência e Aquisição e Técnicas de Trabalho em Grupo nos Setores de Circulação e Aquisição.

$\mathrm{O}$ fato de algum aspecto ser considerado como Muito Importante e Muito Difícil pode ser uma indicação de que haja necessidade de treinamento e atualização para estes gerentes ou mesmo que eles não tiveram ainda acesso formal a estas competências e habilidades. Um projeto de marketing para os Setores de Referência e de Circulação é compreensível, pois estes estão na "linha de frente" de toda a operação da Unidade de Informação e por isto são tidos como os Setores de "relações públicas". A imagem que os clientes terão da Instituição como um todo é grandemente formada através de seu contato com estes setores. Sendo assim, possuir competências em marketing parece ser de extrema importância para qualquer um que trabalhe nestes setores.

Parece-nos que os gerentes que participaram desta investigação e que atuam nos Setores de Referência e Aquisição acertaram ao indicarem que Planejamento Estratégico seja um aspecto Muito Importante. Ao considerarem também como sendo Muito Difícil denota a necessidade de um maior preparo para usar este valioso instrumental. A análise do ambiente externo, a definição de objetivos metas dos serviços de informação que serão ofertados, da clientela que será servida e das condições internas em termos de recursos financeiros, pessoais e físicos são de extrema necessidade para divisar de forma eficaz estes dois setores.

Não fica muito claro para este investigador o motivo dos aspectos Seleção de Pessoal e Técnicas de Trabalho em Grupo serem tidos como Muito Importantes e Muito Difíceis para gerentes que atuam em alguns setores e não em outros. Talvez seja muito mais por deficiências pessoais destes gerentes que qualquer outro fator considerando o ambiente ou a natureza do trabalho destes Setores.

$\mathrm{O}$ aspecto Planejamento de Serviços coincidiu como sendo Muito Importante e Muito Freqüente para 
os gerentes que atuam também nos Setores de Circulação, Referência e Processamento Técnico. O aspecto Controle de Qualidade coincidiu nos Setores de Circulação e de Aquisição e o aspecto Liderança nos Setores de Referência e Aquisição. O aspecto Tomada de Decisão coincidiu nos Setores de Referência e Processamento Técnico.

Os resultados obtidos com relação a esta questão diverge parcialmente do que o autor pensaria ser o esperado. Por exemplo: a) o aspecto Planejamento de Serviços ser considerado como uma prática Muito Freqüente para os gerentes que atuam nos Setores de Referência e Circulação parece ser bastante óbvio, mas o que não fica claro é por que consideram Freqüente a prática deste aspecto gerencial no Setor de Processamento Técnico, onde a ênfase das atìvidades é no sentido de dar apoio, organização e suporte para os demais Setores; b) o aspecto Controle de Qualidade ser considerado Freqüente nos Setores de Circulação e Aquisição e não nos Setores de Referência e Processamento Técnico, quando embora a qualidade seja importante em qualquer setor, parece-nos mais pertinente para estes dois últimos Setores mencionados, pois qualidade no Processamento Técnico é indispensável para o rápido e efetivo acesso aos materiais informacionais e de extrema necessidade no Setor de Referência para que haja um adequado e preciso atendimento às necessidades, solicitações e expectativas dos usuários, o que, afinal, é a finalidade última de qualquer serviço de informação; c) o aspecto Tomada de Decisão não ter sido considerado Muito Freqüente no Setor de Aquisição, pois a eficiência de toda a Unidade de Informação está vinculada, em grande parte, às constantes e necessárias decisões que são tomadas neste Setor.

\section{Experiência No Cargo}

A pesquisa identificou os aspectos gerenciais considerados pelos gerentes como sendo Muito e Pouco Importante, Muito e Pouco Difícil e Muito e Pouco Freqüente levando em consideração a experiência (ou seja, o número de anos) que ocupavam o cargo de gerência ou diretoria. O intuito foi verificar se o tempo no cargo influencia a percepção destes gerentes quanto à Importância dos 35 aspectos gerenciais abordados para o desenvolvimento de suas funções, o grau de Dificuldade que enfrentam ao se depararem com estes aspectos gerenciais bem como a Freqüência com que precisam lidar com cada uma destas atividades gerenciais.

\section{Gerentes Com Até 5 Anos No Cargo}

Diante dos resultados obtidos, pode-se afirmar que estes gerentes, ou seja, gerentes com menos de 6 anos de experiência necessitam de maior treinamento e preparo nos aspectos Avaliação de Serviços, Elaboração de Políticas e Instrumentos de Controle, e Diagnóstico.

\section{Gerentes Com 6 a 10 Anos No Cargo}

Os gerentes com experiência no cargo de direção entre 6 e 10 anos, que participaram deste estudo, indicaram 22 aspectos como sendo Muito Importantes. Destes, 6 foram considerados como sendo apenas Muito Importantes - Uso de Técnicas de Coordenação, Avaliação de Serviços, Planejamento de Serviços, Avaliação de Bibliotecas, Estudos de Comunidades e Planejamento Estratégico.

Os resultados indicam que os profssionais, diretores e gerentes de UI com 6 a 10 anos de experiência poderiam grandemente beneficiar-se de programas de treinamento e educação continuada que envolvessem os aspectos Uso de Técnicas de Organização, Técnicas de Decisão, Estrutura Organizacional, Planejamento, Desenvolvimento e Administração de Projetos, Diagnóstico, Instrumentos de Controle, Resolução de Conflitos, Uso de Técnicas de Direção, Desenvolvimento Organizacional, Marketing, Controle de Qualidade, Planejamento Estratégico, Avaliação de Desempenho, Motivação de Pessoal, e Administração do Tempo.

\section{Gerentes Com 11 a 15 Anos no Cargo}

Os gerentes com experiência média em seus cargos indicaram que todos os aspectos gerenciais abordados são Muito Importantes, sendo que os mais relevantes, por serem Muito Importantes, Muito Difíceis e Muito Freqüentes, são os aspectos Uso de Técnicas de Organização, Estrutura Organizacional e Elaboração de Relatórios.

Apenas 5 aspectos foram considerados como sendo Pouco Importantes por alguns destes gerentes. A saber: Elaboração de Políticas, Instrumentos de Controle, Administração de Stress, Delegação de Poder e Administração de Mudança. Vinte e nove aspectos foram considerados como sendo Pouco Difíceis, e os aspectos Elaboração de Políticas, Instrumentos de Controle, Administração de Stress, $e$ Administração de Mudança foram considerados como 
sendo irrelevantes, pois foram tidos como sendo Pouco Importantes, Pouco Difíceis e Pouco Freqüentes.

Sendo assim, estes gerentes poderiam desenvolver de forma mais eficaz suas funções à frente de seus empreendimentos ao receberem treinamento específico nas áreas de Uso de Técnicas de Organização, Estrutura Organizacional, Elaboração de Relatórios, Planejamento Físico, Estudo de Comunidade, Marketing, Avaliação.

\section{Gerentes Com 16 a 20 Anos no Cargo}

Os gerentes, que possuem entre 16 a 20 anos de experiência em cargos de chefia de UI, consideraram 29 dos 35 aspectos gerenciais abordados como sendo Muito Importantes para desenvolverem suas funções adequadamente.

Alguns gerentes consideraram como sendo de Pouca Importância os aspectos Elaboração de Manuais, Elaboração de Políticas, Elaboração de Relatórios, Determinação de Metas, Avaliação de Bibliotecas, Estudo de Comunidades e Instrumentos de Controle. Os aspectos Elaboração de Políticas. Elaboração de Relatórios, Determinação de Metas, Avaliação de Bibliotecas e Instrumentos de Controle foram tidos como pouco relevantes, pois foram considerados como sendo Pouco Importantes, Pouco Difíceis e Pouco Freqüentes.

Diante dos resultados apresentados, recomendamos aos responsáveis por programas de desenvolvimento gerencial voltados para gerentes com 16 a 20 anos de experiência que incluam de forma prioritária os aspectos Uso de Técnicas de Coordenação, Uso de Técnicas de Organização, Uso de Técnicas de Direção, Desenvolvimento Organizacional, Estrutura Organizacional, Planejamento de Serviços, Planejamento Físico, Elaboração de Políticas. Avaliação de Bibliotecas, Estudo de Comunidade, Marketing, Controle de Qualidade, Planejamento Estratégico, Diagnóstico, Instrumentos de Controle, Avaliação de Desempenho, Motivação de Pessoal, Administração de Stress, Comunicação, Treinamento, Delegação de Poder, Administração de Mudança e Administração do Tempo.

\section{Gerentes Com Mais de 20 anos no Cargo}

Os gerentes com maior número de anos de experiência à frente de suas instituições indicaram 20 aspectos gerenciais como sendo Muito Importantes. Os aspectos Uso de Técnicas de Direção, Avaliação de Serviços, Planejamento Estratégico e Delegação de Poder foram tidos como sendo Muito Importantes, Muito Difíceis e Muito Freqüentes.

Nenhum aspecto foi tido como sendo Pouco Importante ou Pouco Freqüente, e os aspectos Estudo de Comunidade, Elaboração de Orçamento, Marketing, Controle de Qualidade, Resolução de Conflitos e Seleção de Pessoal foram todos percebidos como sendo Pouco Difíceis.

Os resultados podem indicar que os aspectos Uso de Técnicas de Direção, Avaliação de Serviços, Planejamento Estratégico e Delegação de Poder, Controle de Qualidade e Liderança devem ser enfatizados em cursos e programas de treinamento para gerentes de UI mais experientes.

Os dados nos levam a observar que houve bastante variação no número de aspectos considerados Muito Importantes, dependendo da experiência dos sujeitos no cargo de gerência, experiência esta, determinada pelo número de anos ocupando tal posição, muito embora os gerentes com menor experiência (de 0 a 5 anos) tenham relatado o menor número (8) de aspectos considerados Muito Importantes. Os gerentes que ocupavam cargos de gerência entre 11 a 15 anos relataram como sendo Muito Importantes todos os aspectos considerados neste estudo, ou seja, 35, sendo que os que possuíam mais de 20 anos, relataram 20 aspectos.

É possível que gerentes com menor experiência não tenham tido tempo suficiente para vivenciar uma gama maior de atividades que exigissem deles a adoção de grande parte dos aspectos gerenciais possíveis e existentes, o que não lhes permite uma observação mais abalizada.

Houve coincidências com relação aos aspectos considerados Muito Importantes, Muito Difíceis e Muito Freqüentes (ou seja Muito Relevantes). Dentre os mais significativos, destaca-se o aspecto Uso de Técnicas de Organização, que foi considerado como tal para os gerentes com experiência de 6 a 10 anos, de 11 a 15 e de 16 a 20, uma demonstração que este aspecto é muito relevante independente do número de anos de experiência do gerente. De fato, principalmente em se tratando da natureza dos serviços e tarefas próprias de Unidades de Informação, organização será sempre um aspecto preponderante para o desenvolvimento dinâmico e eficaz das atividades.

Os gerentes com experiência média, ou seja, de 6 a 10 anos, de 11 a 15 e de 16 a 20 consideraram relevantes os aspectos Estrutura Organizacional, Diagnóstico e Instrumentos de Controle. Já os gerentes 
com experiência mais elevada, ou seja, de 16 a 20 anos e aqueles, com mais de 20 anos em cargos de gerência, sugerem os aspectos Uso de Técnicas de Direção, Planejamento Estratégico e Delegação de Poder como sendo altamente relevantes.

Gerentes com um certo amadurecimento percebem, conforme indicam os dados, a importância que uma adequada estrutura organizacional tem para que os objetivos sejam alcançados, assim como passam a valorizar a necessidade de diagnósticos e instrumentos de controle, pois passam a reconhecer que sem uma avaliação constante não é possível acompanhar as rápidas mudanças que ocorrem no mundo da tecnologia informacional e nas necessidades dos usuários bem como da sociedade como um todo.

Aqueles com maior experiência valorizam o Planejamento Estratégico e a Delegação de Poder, que podemos considerar como sendo extensões ou mesmo um aprofundamento dos aspectos tidos como relevantes pelos grupos anteriores - estrutura, diagnóstico e instrumentos de controle.

Apenas três aspectos coincidiram quanto ao item Muito Importante e Muito Difícil. Os aspectos Marketing e Avaliação de Desempenho coincidiram nas opiniões dos gerentes com 6 a 10 e de 11 a 15 anos de experiência, uma demonstração que embora considerados como sendo Muito Importantes, estes dois aspectos ainda não são dominados plenamente por gerentes com certa experiência na função. $\mathrm{O}$ aspecto Controle de Qualidade coincidiu para os gerentes com 6-10 e mais de 20 anos de experiência como sendo Muito Importante e Muito Difícil, não sendo encontrado uma tendência ou padrão pertinente.

$\mathrm{O}$ aspecto Tomada de Decisão foi tido como sendo Muito Importante e Muito Freqüente para os gerentes com 0 a 5 anos de experiência, de 11 a 15 e mais de vinte, indicando, portanto, que esta faceta do trabalho gerencial faz parte das atividades de todos os gerentes independente de sua experiência. Os aspectos considerados Freqüentes por gerentes com menor e média experiência (0-5 e de 11 a 15 anos) foram Uso de Técnicas de Coordenação e Uso de Técnicas de Direção. Esperava-se, no entanto, que estes aspectos seriam considerados Freqüentes por todos independente da experiência.

Os aspectos Desenvolvimento Organizacional, Avaliação de Serviços e Planejamento $e$ Desenvolvimento de Projetos foram tidos como sendo Muito Importantes e Muito Freqüentes por gerentes com experiência média e alta (de 11 a 15 e de 16 a 20 anos). Outra vez parece que o amadurecimento e maior consciência por parte dos gerentes das reais necessidades de adaptação tornam estes aspectos mais Freqüentes em seu dia-a-dia. O aspecto Seleção de Pessoal coincidiu entre os gerentes com experiência elevada, ou seja, de 16 a 20 e mais de anos.

\section{Número de Funcionários}

A pesquisa identificou os aspectos gerenciais considerados pelos gerentes como sendo Muito e Pouco Importantes, Muito e Pouco Difíceis e Muito e Pouco Freqüentes levando em consideração o número de funcionários sob seu comando. O intuito foi verificar se o tamanho do quadro de pessoal influencia a percepção destes gerentes quanto à Importância dos 35 aspectos gerenciais abordados para o desenvolvimento de suas funções, o grau de Dificuldade que enfrentam ao se depararem com estes aspectos bem como a Freqüência com que precisam lidar com cada uma destas atividades gerenciais.

\section{De 1 a 10 Funcionários}

Os aspectos tidos por estes gerentes com até 10 funcionários sob sua responsabilidade indicaram como sendo Muito Importantes, Muito Difíceis e Muito Freqüentes, portanto, muito relevantes, foram Técnicas de Organização, Estrutura Organizacional, Avaliação de Serviços, Planejamento, Desenvolvimento e Administração de Projetos, Administração de Mudanças e Administração.

Estes gerentes consideraram os aspectos Desenvolvimento Organizacional, Tomada de Decisão, Elaboração de Relatórios, Determinação de Metas, Objetivos e Missão, e Avaliação de Unidades de Informação como sendo Pouco Importantes e apenas o aspecto Tomada de Decisão foi tido como sendo irrelevante, pois estes gerentes o consideraram como sendo Pouco Importante, Pouco Difícil e Pouco Freqüente, o que na realidade é um resultante bastante duvidoso, pois este é um aspecto do trabalho gerencial de suma importância.

Os resultados podem indicar, ainda, que gerentes com este perfil de trabalho poderiam realizar suas atividades com maior eficiência ao receberem treinamento formal e desenvolverem suas competências nas áreas de Técnicas de Organização, Estrutura Organizacional, Avaliação de Serviços, Planejamento, Desenvolvimento, Administração de Projetos, Administração de Mudanças e Administração do Tempo, Técnicas de Organização, Técnicas de Direção, Estrutura Organizacional, Avaliação de Serviços, 
Planejamento, Desenvolvimento e Administração de Projetos, Planejamento de Serviços, Controle de Qualidade, Diagnóstico, Resolução de Conflitos, Liderança, Administração de Stress, Delegação de Poder, Administração de Mudança, e Administração do Tempo por terem sido considerados como sendo relevantes e também como sendo Muito Importantes e Muito Frequientes.

Os esforços de treinamento informal poderiam abranger aspectos tais como Técnicas de Organização, Estrutura Organizacional, Estrutura Organizacional, Planejamento, Desenvolvimento e Administração de Projetos, Elaboração de Manuais, Elaboração de Políticas, Estudo de Comunidades, Marketing, Planejamento Estratégico, Instrumentos de Controle, Motivação de Pessoal, Seleção de Pessoal, Técnicas de Trabalho em Grupo e Administração do Tempo por terem sido considerados como sendo Muito Importantes e Muito Difíceis.

\section{De 11 a 20 Funcionários}

Os gerentes que possuem sob seu comando de 11 a 20 funcionários deixaram de indicar apenas um aspecto como sendo Muito Importante - ou seja, Instrumentos de Controle. Indicaram como sendo Muito Importantes, Muito Difíceis e Muito Freqüentes, portanto muito relevantes, os aspectos Uso de Técnicas de Coordenação, Planejamento Físico, Desenvolvimento e Administração de Projetos, Elaboração de Manuais, Organização e Métodos, Resolução de Conflitos, Liderança, Administração de Stress, Comunicação, Treinamento, Técnicas de Dirigir Grupos e Delegação de Poder.

Apenas o aspecto Instrumentos de Controle foi considerado como sendo de Pouca Importância para estes gerentes.

Os aspectos Planejamento Físico, Elaboração de Políticas, Determinação de Metas e Objetivos Avaliação de Bibliotecas, Elaboração de Orçamento, Marketing, Controle de Qualidade, Instrumentos de Controle, Avaliação de Desempenho e Seleção de Pessoal merecem ser considerados em projetos ou programas de desenvolvimento profissional, por se tratarem de aspectos tidos como Muito Importantes e também Muito Difíceis pelos gerentes pesquisados.

\section{Mais de 20 Funcionários}

Todos os aspectos abordados foram tidos como sendo Muito Importantes pelos gerentes que comandam mais de 20 funcionários, sendo que apenas dois aspectos foram tidos como sendo Muito Importantes, Muito Difíceis e Muito Freqüentes, ou seja, Uso de Técnicas de Direção e Elaboração de Políticas.

Estes dados, bem como outros levantados no estudo, revelam, levando em consideração a opinião dos gerentes que participaram do estudo, que os aspectos mais relevantes são Uso de Técnicas de Direção e Elaboração de Políticas e, portanto, devem ser incluídos nos cursos formais de preparação de gerentes de grandes unidades de informação. Já os aspectos Uso de Técnicas de Direção e Elaboração de Políticas, Planejamento de Serviços, Elaboração de Orçamento, Marketing, Controle de Qualidade, Diagnóstico, Técnicas de Seleção, e Treinamento devem fazer parte de esforços de educação continuada e treinamento para gerentes com tais responsabilidades e perfil.

Algumas coincidências podem ser destacadas. Os aspectos Planejamento, Desenvolvimento $e$ Administração de Projetos (8), Administração de Stress (28) e Administração do Ternpo (35) foram tidos como Muito Importantes, Muito Difícil e Muito Freqüentes para os gerentes responsáveis por equipes de até 20 funcionários. Em realidade estes dados são um tanto surpreendentes, pois era de esperar-se que quanto maior fosse o número de funcionários maior seria a necessidade de gerenciar o stress e o tempo.

Os aspectos gerenciais Marketing e Técnicas de Seleção de Pessoal foram tidos como Muito Importantes e Muito Difíceis pelos três grupos, ou seja, estes aspectos são considerados como tal independente do tamanho da equipe. Já os aspectos Elaboração de Políticas, Avaliação de Bibliotecas e Avaliação de Desempenho pelos gerentes que possuem equipes de até 20 funcionários. O aspecto Elaboração de Orçamento foi tido como tal por gerentes com equipes de 1 a 10 e mais de 20 funcionários.

Estes dados demonstram que os aspectos acima citados devem ser priorizados e levados a sério por todos os gerentes, pois não importa o tamanho da equipe, são áreas que afetam de forma marcante o andamento das atividades da Instituição. Uma seleção mal feita, mesmo sendo apenas de 1 funcionário pode acarretar problemas de todas as ordens, atitude, comportamento, relacionamento, competência, etc., comprometendo a eficiência dos serviços prestados. A falta de um programa de marketing bem estruturado e planejado pode ser decisivo para o enfraquecimento da imagem, uso, benefício e impacto que a Unidade de Informação possa ter na comunidade que é de sua responsabilidade servir.

O aspecto Tomada de Decisão foi considerado Muito Importante e Muito Freqüente pelos gerentes 
independente do tamanho da equipe de trabalho. Os aspectos Uso de Técnicas de Organização, e Avaliação de Serviços por gerentes com equipes de até 20 funcionários, e o aspecto Resolução de Conflito por gerentes com equipes menores (de 1 a 10 funcionários) e maiores (mais de 20 funcionários).

O fato do aspecto gerencial Tomada de Decisão ter sido considerado Muito Freqüente pelos gerentes com equipes de todos os tamanhos não é de surpreender, pois decisões precisam ser tomadas constantemente talvez mais em função dos ajustes, planos e projetos necessários para compatibilizar a organização com seu meio ambiente do que propriamente em função das pessoas que ali trabalham. No entanto, pareceria lógico que quanto maior fosse a organização, maior o número de serviços que ela estaria prestando. Conseqüentemente, maior seria a necessidade de avaliações periódicas do desempenho destas ofertas. Em realidade, não foi isto que o estudo demonstrou através dos resultados obtidos e demonstrados.

\section{CONCLUSÕES}

Este trabalho objetivou identificar, em primeira instância, se havia alguma relação de impacto entre alguns fatores contextuais do trabalho do gerente de UI, tais como, Setores onde eles poderiam estar acumulando atividades, experiência como gerentes, em termos de número de anos atuando em tal posição e tamanho da equipe de trabalho, ou seja, o número de funcionários sob seu comando e sua percepção quanto à relevância de 35 aspectos gerenciais para a execução de um trabalho profícuo.

Os resultados obtidos permitem concluir que existem alguns aspectos gerenciais de suma relevância para o trabalho gerencial independente dos fatores levados em consideração e analisados neste estudo. Estes aspectos são aqueles que coincidiram como sendo Muito Importante, Muito Difícil e Muito Freqüente nos três fatores abordados, ou seja, Setores onde os gerentes também possuam responsabilidades, Experiência dos gerentes em cargos de comando (em termos de número de anos) e Tamanho da Equipe de trabalho, em termos de número de funcionários.

Apenas o aspecto Uso de Técnicas de Organização e Administração de Stress são relevantes para os gerentes de uma forma geral, pois o primeiro foi tido como sendo Muito Importante, Muito Difícil e Muito Freqüente para os gerentes que atuam em qualquer um dos Setores identificados e independente do número de anos que atuam como líderes de suas Unidades de
Informação. Já o segundo aspecto foi tido como tal pelos gerentes que atuam em qualquer um dos Setores assim como independente do Tamanho da Equipe de trabalho em termos do número de funcionários.

Quanto aos aspectos gerenciais que merecem fazer parte de esforços informais de treinamento e desenvolvimento para aumentar a competência dos gerentes de Unidades de Informação, de uma forma geral, estão Marketing, Avaliação de Desempenho e Seleção de Pessoal por terem sido considerados como Muito Importante e Muito Difícil pelos gerentes que participaram do estudo.

Os aspectos Tomada de Decisão e Avaliação de Serviços devem fazer parte de uma forma geral dos programas formais de treinamento de profissionais da informação visando oferecer habilidades gerenciais, pois o primeiro foi tido como sendo Muito Importante e Muito Freqüente pelos gerentes que atuam em qualquer um dos Setores, independente de sua experiência e tamanho de sua equipe de trabalho. O segundo foi considerado como tal pelos gerentes independente de sua experiência e tamanho da equipe sob seu comando.

Em última análise, esta pesquisa demonstrou que os gerentes de Unidades de Informação necessitam de competências em diversos aspectos gerenciais para que sua função como líderes e diretores seja realizada com êxito. Os aspectos gerenciais necessários para alcançarem tal êxito podem variar em função de alguns fatores pessoais ou próprios do contexto onde atuam.

Alguns destes fatores, tais como: a) setores dentro das Unidades onde também atuam de forma regular; b) experiência na função de gerência em termos de números de anos e c) tamanho da equipe (número de funcionários sob seu comando) foram considerados neste estudo.

Assim, os resultados obtidos indicam que:

1. o fato do gerente de Unidade de Informação ter responsabilidades adicionais em algum Setor pode influenciar sua percepção quanto aos aspectos gerenciais relevantes para a execução de sua função como gerente. Assim, o Setor onde o gerente também atua possui um impacto nas habilidades gerencias consideradas relevantes;

2. o fator "experiência" na gerência não possui um impacto significativo na percepção dos gerentes de U.I. quanto aos aspectos gerenciais relevantes para realizarem um trabalho eficaz;

3. o tamanho da equipe possui um impacto na percepção dos gerentes de UI em termos de aspectos gerenciais considerados relevantes;

4. os programas de formação básica visando preparar profissionais da informação para cargos de 
chefia deveriam, conforme os resultados deste estudo, incluir no conteúdo destes programas aspectos gerenciais diferenciados para atender às exigências e especificidades gerenciais dos diferentes Setores das Unidades de Informação;

5. aspectos gerenciais diferenciados devem ser enfatizados em esforços informais de treinamento e desenvolvimento dependendo dos Setores de Atuação dos gerentes de UI;

6. diferentes tópicos (aspectos gerenciais) devem ser abordados em iniciativas informais de treinamento e aperfeiçoamento dependendo da experiência dos gerentes em termos de número de anos que ocupam cargos de comando;

7. os cursos de formação básica devem, até certo ponto, enfatizar diferentes aspectos gerenciais em seus programas se levarem em consideração o tamanho da equipe que o "futuro" gerente terá sob seu comando;

8. os programas informais de treinamento e desenvolvimento gerencial de gerentes de unidades de informação deveriam considerar o tamanho da equipe ao desenvolverem o conteúdo de tais iniciativas;

9. poucos aspectos são tidos como relevantes, de uma forma geral, quando todos os fatores considerados neste estudo são agrupados.

Recomendamos, por fim, que futuros estudos abordem e considerem outros fatores, tanto pessoais (formação básica, idade, sexo, etc.) quanto contextuais (área de especialização da Unidade de Informação, posicionamento dentro da hierarquia da organização, etc.) para alargar os horizontes desta pesquisa assim como utilizem uma metodologia mais qualitativa, tipo entrevista, observação direta e incidente crítico, por exemplo.

A tecnologia informacional existe. Possuímos bases bibliográficas, OPACs integrados, pesquisas em discos, Internet e bibliotecas virtuais. O desafio diante de nós é construir uma estrutura organizacional que permitirá o uso desta tecnologia de forma criativa e eficaz.

Para isto, faz-se necessário ver além das preocupações imediatas da biblioteca e perceber as tendências ambientais. A adoção de planejamento estratégico precisa levar em consideração quão crítico é a infra estrutura da IT para a missão da biblioteca.

Um passo importante, após os objetivos terem sido esclarecidos, e os planos terem sido desenvolvidos, é realizar uma auditoria de necessidades de RH. Calcular quantas pessoas, em quais níveis, e quais habilidades serão necessárias a curto e médio prazo.
Se for detectado a necessidade de habilidades específicas, ou o pessoal existente deverá ser treinado ou providências devem ser tomadas para novas contratações.

Precisamos recrutar e desenvolver pessoal que adentrem a profissão não em busca de segurança ou estrutura, mas em busca de excitamento intelectual e a oportunidade de moldar um novo mundo, e precisamos começar a buscar e recompensar criatividade e energia da mesma forma que nós temos tradicionalmente valorizado experiência, conhecimento profissional e dependabilidade (Taylor, 1995).

Os paradoxos são grandes e difíceis, mas podemos apenas reconhecer o papel de liderança que aguarda os profissionais da informação e, como educadores, garantir que estejam preparados para aplicar uma variedade de habilidades interpessoais e criar estruturas institucionais que promoverão a autorealização pessoal dos funcionários como uma das metas primárias da organização.

As dificuldades surgem da natureza complexa, ambígua e dinâmica das organizações e dos indivíduos. Ambos são sujeitos a pressões internas e externas que podem dificultar compatibilizar as necessidades individuais com as organizacionais em um determinado momento. O que é requerido do gerente é a habilidade de lidar com ambigüidade, ser flexível, e acima de tudo, ser criativo.

Sendo que muitos aspectos da cultura organizacional são intangíveis, o gerente precisa articular claramente os valores e normas aceitáveis e não aceitáveis num ambiente que depende de "expertise compartilhado" e cooperação entre colegas. Neste processo, o gerente precisa comunicar a história da estrutura organizacional e ao mesmo tempo enfatizar que a adaptação à cultura corporativa contribui para o sucesso no trabalho (Nofsinger e Bosch,1994).

A confiança que os diretores conseguirão construir ao redor de sua liderança dependerá de suas habilidades de responder aos fatores externos, influenciar os valores sociais da biblioteca e adotar a tecnologia informacional emergente, assim como gerenciar os recursos internos da biblioteca num ambiente de economia cada vez mais escassa.

Como as verbas institucionais estão se tornando cada vez menos acessíveis é imperativo que o diretor busque os recursos financeiros de outras alternativas. É papel do diretor identificar agências e fundações que freqüentemente não possuem conhecimento ou mesmo compreensão do impacto dos serviços da biblioteca na sociedade, e convencê-los da importância e valor de apoiar as necessidades e iniciativas. 
A redefinição das bibliotecas frente aos novos desafios, com certeza afetará o conteúdo do trabalho de cada membro da organização e mudará significativamente o papel e funções do pessoal, tornando as estruturas organizacionais bem diferentes das atuais. Nossa meta como profissionais da informação é maximizar nossos recursos para servir os usuários de forma mais eficaz e dinâmica possível. Uma revolução na tecnologia informacional está ocorrendo. É uma revolução que irá essencialmente abalar a eficácia dos métodos administrativos autoritários, tradicionais e científicos, e irá, sem dúvida, levar a mudanças profundas nas bibliotecas, nas funções dos bibliotecários e expectativas dos usuários.

O futuro depende de nós. Veaner (1985), há mais de dez anos atrás, já nos conclamava para liderar estas mudanças, e não permitir que fôssemos arrastados por elas. Devemos aceitar o desafio e assumir uma postura administrativa condizente com o contexto informacional de nossa época.

\section{REFERÊNCIAS BIBLIOGRÁFICAS}

ABELL, Angela. (1997) The Library Association Record, v. 99 , n.10, p. 538-539, oct.

ADAMS, R.J. ( 1986) Information technology and libraries: a future for academic libraries. London: Croom Helm.

ALBRITTON, R.L. \& SHAUGHNESSY, T.W. (1990) Developing leadership skills: a source book for librarians. Englewood: Librries Unlimited.

ANDERSON, U. (1977) Management training for librarians: London: Library Association. (Library Association Research Publ., n.18)

BAKER, D. (1988) Management of change or change of management. Education Libraries Bulletin, v. 31, n. 3, pp. 8-17.

BAUGHMAN, J. (1980) The invisible director: the emerging metropolitan library executive. Library Journal, v. 105, n. 12 , pp.1357-1361.

BATTIN, Patricia. (1984) The library: center of the restructured university. College \& Researach Libraries, v. 45, n. 174 , pp.12-23.

BENNIS, Warren G. \& SLATER, Philip E. (1968) The temporary society. New York: Harper and Row.

BIRDSALL, William F. (1990) The library manager as therapist. The Journal of Academic Librarianship, v. 16, n. 4, pp. 209-212.

BRINDLEY, L. (1987) Management development for the information professionals of the future. Aslib Proceedings, v. 39, n. 9, pp. 235-43.

BOYLE, R.J. (1984) Wrestling with jellyfish. Harvard Business Review, v. 62 pp. 74-83.
CORRALL, Sheila. (1994a) Fieldman: human resource management. Library Association Record, v. 96, n. 8, pp. 418-432.

CORRAL, Sheila. (1994b) Management development in academic libraries and The Joint Funding Council's librararies review. British Journal of Academic Libraries, v.9, n.3, pp. 209-223.

COTTAM, Keith M. (1994) Directors of large libraries: roles, functions, and activities. Library Trends, v. 43, n.1, pp.15-33.

CORCORAM, Mary \& JONES, Rebecca. (1997) Chief knowlidge officers?: perceptions, pitfalls, \& potential. Information Outlook, june, p. 30-31.

DRUCKER, P. (1980) Managing in turbulent times. New York: Harper \& Row.

DRUCKER, P. (1989) The new realities. New York: Harper \& Row.

EUSTER. J.R. (1987) The academic library director: management activities and effectiveness. New York: Greenwood Press.

FIELDMAN, John. (1993) Supporting expansion: a report on human resource management in academic libraries, for the Joint Funding Council's Libraries Review Group. BristoI: HEFC for England. In: CORRAL, Sheila. (1994b) Management development in academic libraries and the Joint Funding Council' librararies review. British Journal of Academic Libraries, v.9, n.3, pp. 209-223.

GESSESSE, Kebede. (1997) Re-examining the role of the public services librarian in the new information age. Library Review, v. 46, n. 2, p. 90-98.

HAYES, R.M. (1989) A long view of a broad scence. London: British Library. (British Library R \& D Report, 6049).

HISLE, W. Lee. (1997) Facing the new millennium. College \& Research Libraries News, dec., p. 764-5.

HOLLEY, E.G. (1972) Organization and administration of urban university libraries. College and Research Libraries, v.33, n. 3, pp.175-189.

HUBER, G.P. (1984) The nature and design of post-industrial organizations. Management Science, v. 30, pp. 928-951.

HYAMS, Elspeth. (1997) The Electronic Library, v.15, n. 6, dec., p. 455-462.

JAMES, Sylvia. (1989) Understanding managerial principles and practices: management training for business information professionals. Education for Information, v. 7, pp. 355-363.

JOHNSON, I.M. ( 1992) Management education and training for librarians in Scotland. Scottish Libraries, v.3, n. 1, pp. 11-13.

JUROW, S. \& WEBSTER, D. (1990) Promoting management excellence in research libraries through trainning and staff development. Library Administration and Management, v. 4 , n. 3 , pp.141-144. 
KANTER, R.M. (1983). The change masters: innovation and entrepreneurship in the American Corporation. New York: Simon \& Schuster. Apud. LEWIS, D.W. An organizational paradigm for effective academic libraries. College \& Research Libraries, v. 47, n. 4, pp. 348.

LEE, S.A. (1977) Conflict and ambiguity in the role of the academic library director. College \& Research Libraries, v. 38 , n. 5, pp. 396-403.

LEWIS, D.W. (1986) An organizational paradigm for effective academic libraries. College \& Research Libraries, v. 47, n. 4, pp. 337-353.

LINE, Maurice B. (1994) Library management styles and structures: a need to rethink? Journal of Librarianship and Information Science, v. 23, n. 2 pp. 97-104.

LINE, M. B. \& ROBERTSON, K. (1989) Staff development in libraries. British Journal of Academic Librarianship, v. 4, n. 3, pp.161-174.

MALLEY, I. (1994) Cash is the key for management training. Library Associatio Record, v. 94, n.12, pp. 792-79.

MARCHANT, M.P. \& ENGLAND, M.M. (1989) Changing management techniques as libraries automate. Library Trends, v. 37, n. 2, pp. 469-83.

MARTIN, Susan K. (1989) Library management and emerging technology: the immovable force and the irresistible object. Library Trends, v.37, n. 3, pp. 374-382.

McANALLY, A.M. \& DOWNS, R.B. (1973) The changing role of directors of univeristy libraries. College $\boldsymbol{\&}$ Research Libraries, v. 34, n. 2, pp. 103-125.

MECH, T.F. (1989) Public library directors: a career and managerial profile. Public Libraries, v. 28, n. 4, pp. 228-235.

MECH, T.F. (1990) Academic library directors: a managerial role profile.College $\&$ Research Libraries, v. 51, n. 5, pp. 415-428.

METZ, P. (1979) The role of the academic library director. Journal of Academic Librarianship, v. 5, n. 3, pp. 148-152.

MITCHELL, C.A. (1992) The CLR Academic Library Management Intern Program Library Administration and Management, v.6, n.1, pp. 29-35.

MOORE, Mary. (1995) Impact of the changing environment on academic library administration: conflicts, incongruities, contradictions and dichotomies. Journal of Library Administration, v. 22, n.1, pp. 13-38.

MOSKOWITZ, M.A.(1986) The managerial roles of academic library directors: the Mintzberg model. College \& Research Libraries, v. 47, n. 5, pp. 452-459.
NOFSINGER, Mary M. \& BOSCH, Allan W. (1994) Roles of the head of reference: from the 1990 s to the 21 st century. The Reference Librarian, n. 43, pp. 87-99.

PEEL, Malcolm. (1989) Do libraries need managers? Aslib Information, v. 18, n. 9, p. 288.

PITTS, Roberta L. (1944) A generalist in the age of specialists: a profile of the one-person library director. Library Trends, v. 43, n.1, pp.121-35.

RITCHIE, S. (1988) Training and management development in librarianship. London: Briotish Libriry. (Library and Information Research Report, 34)

ROOKS, Dana C. (1994) Terms for academic library directors. Library Trends, v. 43, n.1, pp. 47-61.

SAGER, D.J. (1982) Participatory management in libraries. Metuchen, NJ: Scarecrow.

SAFFORD, H.D. (1988) Small college library directors. In: McCAbe, G.B. (ed.) The smaller academic library. New York: Greenwood Press, pp.19-29.

SHAUGHNESSY, T.W. (1996) The library director as change agent. Journal of Library Administration, v. 22, n. 2/3, pp. 43-56.

TAYLOR, Merrily E. (1995) Getting it all together: leadership requirements for the future of information services. Journal of Library Administration, v. 20, n. 3/4, pp.9-24.

TAYLOR, Valorie \& RENZULLI, Gianna. (1997) Mastering middle management. Information Outlook, feb., p. 18.

VEANER. A.B. (1985) 1985-1985: The next decade in academic librarianship, part 1. College $\&$ Research Libraries, v. 46 , pp. $220-232$.

VEANER, A. B. (1990) Academic librarianship in a transformational age: program, politics, and personnel. Boston: G.K. Hall.

VEROFF, Joseph et al. (1981) The inner american: a self-portrait from 1957 to 1976. New York: Basic Books.

WEBB, Sylvia P. Thoroughbred ou hybrid - the information manager in the 90s? (1997) Information Management Report, Oct., p.1-5.

WITTENBACH, S.A.; BORDEIANU, S.M. \& WYCISK, K. (1992) Management preparation and training of department heads in ARL libraries. College \& Research Libraries, v. 53, n. 4, pp. 319-330.

WOODSWORTH, Anne. New library competencies. (1997) Library Journal, may 15, p. 46. 


\section{ANEXO \\ INSTRUMENTO DE PESQUISA \\ ASPECTOS ADMINISTRATIVOS}

INSTRUÇÕES: Favor indicar para cada aspecto gerencial (A) o grau de importância que você atribui para o sucesso administrativo de uma Unidade de informação ( 1 = Pouco Importante; 5 = Muito Importante); (B) o grau de dificuldade que você sente com relação a cada aspecto ( 1 = Pouca Dificuldade; $5=$ Muita Dificuldade); (C) com que freqüência você precisa lidar com estes aspectos em seu ambiente de trabalho ( 1 = Pouca Freqüência; 5 = Muita Freqüência).

\begin{tabular}{|l|l|l|}
\hline ASPECTOS GERENCIAIS & A - POUCA IMPORTÂNCIA & A - MUITO IMPORTANTE \\
& B - POUCA DIFICULDADE & B - MUITA DIFICULDADE \\
& C - POUCA FREQÜÊNCIA & C - MUITA FREQÜÊNCIA \\
\hline
\end{tabular}

\begin{tabular}{|c|c|c|c|c|c|c|}
\hline 1. Técnicas de Coordenação & $\begin{array}{l}\text { A } \\
\text { B } \\
\text { C }\end{array}$ & $\begin{array}{l}1 \\
1 \\
1\end{array}$ & $\begin{array}{l}2 \\
2 \\
2\end{array}$ & $\begin{array}{l}3 \\
3 \\
3\end{array}$ & $\begin{array}{l}4 \\
4 \\
4\end{array}$ & $\begin{array}{l}5 \\
5 \\
5\end{array}$ \\
\hline 2. Técnicas de Organização & $\begin{array}{l}\text { A } \\
\text { B } \\
\text { C }\end{array}$ & $\begin{array}{l}1 \\
1 \\
1\end{array}$ & $\begin{array}{l}2 \\
2 \\
2\end{array}$ & $\begin{array}{l}3 \\
3 \\
3\end{array}$ & $\begin{array}{l}4 \\
4 \\
4\end{array}$ & $\begin{array}{l}5 \\
5 \\
5\end{array}$ \\
\hline 3. Técnicas de Direção & $\begin{array}{l}\text { A } \\
\text { B } \\
\text { C }\end{array}$ & $\begin{array}{l}1 \\
1 \\
1\end{array}$ & $\begin{array}{l}2 \\
2 \\
2\end{array}$ & $\begin{array}{l}3 \\
3 \\
3\end{array}$ & $\begin{array}{l}4 \\
4 \\
4\end{array}$ & $\begin{array}{l}5 \\
5 \\
5\end{array}$ \\
\hline $\begin{array}{l}\text { 4. Dese n volvi me n to } \\
\text { Organizacional }\end{array}$ & $\begin{array}{l}\text { A } \\
\text { B } \\
\text { C }\end{array}$ & $\begin{array}{l}1 \\
1 \\
1 \\
\end{array}$ & $\begin{array}{l}2 \\
2 \\
2\end{array}$ & $\begin{array}{l}3 \\
3 \\
3\end{array}$ & $\begin{array}{l}4 \\
4 \\
4\end{array}$ & $\begin{array}{l}5 \\
5 \\
5\end{array}$ \\
\hline 5. Tomada de Decisão & $\begin{array}{l}\text { A } \\
\text { B } \\
\text { C }\end{array}$ & $\begin{array}{l}1 \\
1 \\
1\end{array}$ & $\begin{array}{l}2 \\
2 \\
2 \\
\end{array}$ & $\begin{array}{l}3 \\
3 \\
3 \\
\end{array}$ & $\begin{array}{l}4 \\
4 \\
4\end{array}$ & $\begin{array}{l}5 \\
5 \\
5\end{array}$ \\
\hline 6. Estrutura Organizacional & $\begin{array}{l}\text { A } \\
\text { B } \\
\text { C }\end{array}$ & $\begin{array}{l}1 \\
1 \\
1\end{array}$ & $\begin{array}{l}2 \\
2 \\
2\end{array}$ & $\begin{array}{l}3 \\
3 \\
3\end{array}$ & $\begin{array}{l}4 \\
4 \\
4\end{array}$ & $\begin{array}{l}5 \\
5 \\
5\end{array}$ \\
\hline 7. Avaliação de Serviços & $\begin{array}{l}\text { A } \\
\text { B } \\
\text { C }\end{array}$ & $\begin{array}{l}1 \\
1 \\
1\end{array}$ & $\begin{array}{l}2 \\
2 \\
2\end{array}$ & $\begin{array}{l}3 \\
3 \\
3\end{array}$ & $\begin{array}{l}4 \\
4 \\
4\end{array}$ & $\begin{array}{l}5 \\
5 \\
5\end{array}$ \\
\hline $\begin{array}{l}\text { 8. Planejamento, Desenvolv. } \\
\text { e Administração de } \\
\text { Projetos }\end{array}$ & $\begin{array}{l}\text { A } \\
\text { B } \\
\text { C }\end{array}$ & $\begin{array}{l}1 \\
1 \\
1\end{array}$ & $\begin{array}{l}2 \\
2 \\
2\end{array}$ & $\begin{array}{l}3 \\
3 \\
3\end{array}$ & $\begin{array}{l}4 \\
4 \\
4\end{array}$ & $\begin{array}{l}5 \\
5 \\
5\end{array}$ \\
\hline 9. Planejamento de Serviços & $\begin{array}{l}\text { A } \\
\text { B } \\
\text { C }\end{array}$ & $\begin{array}{l}1 \\
1 \\
1\end{array}$ & $\begin{array}{l}2 \\
2 \\
2\end{array}$ & $\begin{array}{l}3 \\
3 \\
3\end{array}$ & $\begin{array}{l}4 \\
4 \\
4\end{array}$ & $\begin{array}{l}5 \\
5 \\
5\end{array}$ \\
\hline 10. Planejamento Físico & $\begin{array}{l}\text { A } \\
\text { B } \\
\text { C }\end{array}$ & $\begin{array}{l}1 \\
1 \\
1\end{array}$ & $\begin{array}{l}2 \\
2 \\
2\end{array}$ & $\begin{array}{l}3 \\
3 \\
3\end{array}$ & $\begin{array}{l}4 \\
4 \\
4\end{array}$ & $\begin{array}{l}5 \\
5 \\
5\end{array}$ \\
\hline
\end{tabular}




\begin{tabular}{|c|c|c|c|c|c|c|}
\hline 11. Elaboração de Manuais & $\begin{array}{l}\text { A } \\
\text { B } \\
\text { C }\end{array}$ & $\begin{array}{l}1 \\
1 \\
1\end{array}$ & $\begin{array}{l}2 \\
2 \\
2\end{array}$ & $\begin{array}{l}3 \\
3 \\
3\end{array}$ & $\begin{array}{l}4 \\
4 \\
4\end{array}$ & $\begin{array}{l}5 \\
5 \\
5\end{array}$ \\
\hline 12. Elaboração de Políticas & $\begin{array}{l}\text { A } \\
\text { B } \\
\text { C }\end{array}$ & $\begin{array}{l}1 \\
1 \\
1\end{array}$ & $\begin{array}{l}2 \\
2 \\
2\end{array}$ & $\begin{array}{l}3 \\
3 \\
3\end{array}$ & $\begin{array}{l}4 \\
4 \\
4\end{array}$ & $\begin{array}{l}5 \\
5 \\
5\end{array}$ \\
\hline 13. Elaboração de Relatórios & $\begin{array}{l}\mathrm{A} \\
\mathrm{B} \\
\mathrm{C}\end{array}$ & $\begin{array}{l}1 \\
1 \\
1 \\
\end{array}$ & $\begin{array}{l}2 \\
2 \\
2\end{array}$ & $\begin{array}{l}3 \\
3 \\
3\end{array}$ & $\begin{array}{l}4 \\
4 \\
4\end{array}$ & $\begin{array}{l}5 \\
5 \\
5\end{array}$ \\
\hline $\begin{array}{l}\text { 14. Determinação de Metas, } \\
\text { Objetivos e Missão }\end{array}$ & $\begin{array}{l}\text { A } \\
\text { B } \\
\text { C }\end{array}$ & $\begin{array}{l}1 \\
1 \\
1 \\
\end{array}$ & $\begin{array}{l}2 \\
2 \\
2\end{array}$ & $\begin{array}{l}3 \\
3 \\
3\end{array}$ & $\begin{array}{l}4 \\
4 \\
4 \\
\end{array}$ & $\begin{array}{l}5 \\
5 \\
5 \\
\end{array}$ \\
\hline $\begin{array}{l}\text { 15. Avaliação de Unidade de } \\
\text { Informação }\end{array}$ & $\begin{array}{l}\text { A } \\
\text { B } \\
\text { C }\end{array}$ & $\begin{array}{l}1 \\
1 \\
1\end{array}$ & $\begin{array}{l}2 \\
2 \\
2\end{array}$ & $\begin{array}{l}3 \\
3 \\
3\end{array}$ & $\begin{array}{l}4 \\
4 \\
4\end{array}$ & $\begin{array}{l}5 \\
5 \\
5\end{array}$ \\
\hline 16. Estudo de Comunidade & $\begin{array}{l}\text { A } \\
\text { B } \\
\text { C }\end{array}$ & $\begin{array}{l}1 \\
1 \\
1\end{array}$ & $\begin{array}{l}2 \\
2 \\
2\end{array}$ & $\begin{array}{l}3 \\
3 \\
3\end{array}$ & $\begin{array}{l}4 \\
4 \\
4 \\
\end{array}$ & $\begin{array}{l}5 \\
5 \\
5 \\
\end{array}$ \\
\hline 17. Elaboração de Orçamento & $\begin{array}{l}\text { A } \\
\text { B } \\
\text { C }\end{array}$ & $\begin{array}{l}1 \\
1 \\
1 \\
\end{array}$ & $\begin{array}{l}2 \\
2 \\
2 \\
\end{array}$ & $\begin{array}{l}3 \\
3 \\
3 \\
\end{array}$ & $\begin{array}{l}4 \\
4 \\
4 \\
\end{array}$ & $\begin{array}{l}5 \\
5 \\
5 \\
\end{array}$ \\
\hline 18. Marketing & $\begin{array}{l}\text { A } \\
\text { B } \\
\text { C }\end{array}$ & $\begin{array}{l}1 \\
1 \\
1 \\
\end{array}$ & $\begin{array}{l}2 \\
2 \\
2\end{array}$ & $\begin{array}{l}3 \\
3 \\
3 \\
\end{array}$ & $\begin{array}{l}4 \\
4 \\
4 \\
\end{array}$ & $\begin{array}{l}5 \\
5 \\
5 \\
\end{array}$ \\
\hline 19. Controle de Qualidade & $\begin{array}{l}\text { A } \\
\text { B } \\
\text { C }\end{array}$ & $\begin{array}{l}1 \\
1 \\
1 \\
\end{array}$ & $\begin{array}{l}2 \\
2 \\
2 \\
\end{array}$ & $\begin{array}{l}3 \\
3 \\
3 \\
\end{array}$ & $\begin{array}{l}4 \\
4 \\
4 \\
\end{array}$ & $\begin{array}{l}5 \\
5 \\
5 \\
\end{array}$ \\
\hline 20. Organização e Métodos & $\begin{array}{l}\text { A } \\
\text { B } \\
\text { C }\end{array}$ & $\begin{array}{l}1 \\
1 \\
1 \\
\end{array}$ & $\begin{array}{l}2 \\
2 \\
2 \\
\end{array}$ & $\begin{array}{l}3 \\
3 \\
3 \\
\end{array}$ & $\begin{array}{l}4 \\
4 \\
4 \\
\end{array}$ & $\begin{array}{l}5 \\
5 \\
5 \\
\end{array}$ \\
\hline 21. Planejamento Estratégico & $\begin{array}{l}\text { A } \\
\text { B } \\
\text { C }\end{array}$ & $\begin{array}{l}1 \\
1 \\
1 \\
\end{array}$ & $\begin{array}{l}2 \\
2 \\
2 \\
\end{array}$ & $\begin{array}{l}3 \\
3 \\
3 \\
\end{array}$ & $\begin{array}{l}4 \\
4 \\
4 \\
\end{array}$ & $\begin{array}{l}5 \\
5 \\
5 \\
\end{array}$ \\
\hline 22. Diagnóstico & $\begin{array}{l}\text { A } \\
\text { B } \\
\text { C }\end{array}$ & $\begin{array}{l}1 \\
1 \\
1 \\
\end{array}$ & $\begin{array}{l}2 \\
2 \\
2\end{array}$ & $\begin{array}{l}3 \\
3 \\
3\end{array}$ & $\begin{array}{l}4 \\
4 \\
4\end{array}$ & $\begin{array}{l}5 \\
5 \\
5 \\
\end{array}$ \\
\hline 23. Instrumentos de Controle & $\begin{array}{l}\text { A } \\
\text { B } \\
\text { C }\end{array}$ & $\begin{array}{l}1 \\
1 \\
1 \\
\end{array}$ & $\begin{array}{l}2 \\
2 \\
2\end{array}$ & $\begin{array}{l}3 \\
3 \\
3\end{array}$ & $\begin{array}{l}4 \\
4 \\
4 \\
\end{array}$ & $\begin{array}{l}5 \\
5 \\
5 \\
\end{array}$ \\
\hline 24. Avaliação de Desempenho & $\begin{array}{l}\text { A } \\
\text { B } \\
\text { C }\end{array}$ & $\begin{array}{l}1 \\
1 \\
1 \\
\end{array}$ & $\begin{array}{l}2 \\
2 \\
2\end{array}$ & $\begin{array}{l}3 \\
3 \\
3 \\
\end{array}$ & $\begin{array}{l}4 \\
4 \\
4 \\
\end{array}$ & $\begin{array}{l}5 \\
5 \\
5 \\
\end{array}$ \\
\hline 25. Motivação de Pessoal & $\begin{array}{l}\text { A } \\
\text { B } \\
\text { C }\end{array}$ & $\begin{array}{l}1 \\
1 \\
1 \\
\end{array}$ & $\begin{array}{l}2 \\
2 \\
2\end{array}$ & $\begin{array}{l}3 \\
3 \\
3\end{array}$ & $\begin{array}{l}4 \\
4 \\
4 \\
\end{array}$ & $\begin{array}{l}5 \\
5 \\
5\end{array}$ \\
\hline 26. Resolução de Conflitos & $\begin{array}{l}\text { A } \\
\text { B } \\
\text { C }\end{array}$ & $\begin{array}{l}1 \\
1 \\
1\end{array}$ & $\begin{array}{l}2 \\
2 \\
2\end{array}$ & $\begin{array}{l}3 \\
3 \\
3\end{array}$ & $\begin{array}{l}4 \\
4 \\
4\end{array}$ & $\begin{array}{l}5 \\
5 \\
5\end{array}$ \\
\hline
\end{tabular}




\begin{tabular}{|c|c|c|c|c|c|c|}
\hline 27. Liderança & $\begin{array}{l}\mathrm{A} \\
\mathrm{B} \\
\mathrm{C}\end{array}$ & $\begin{array}{l}1 \\
1 \\
1\end{array}$ & $\begin{array}{l}2 \\
2 \\
2\end{array}$ & $\begin{array}{l}3 \\
3 \\
3 \\
\end{array}$ & $\begin{array}{l}4 \\
4 \\
4\end{array}$ & $\begin{array}{l}5 \\
5 \\
5\end{array}$ \\
\hline 28. Administração de Stress & $\begin{array}{l}\text { A } \\
\text { B } \\
\text { C }\end{array}$ & $\begin{array}{l}1 \\
1 \\
1\end{array}$ & $\begin{array}{l}2 \\
2 \\
2\end{array}$ & $\begin{array}{l}3 \\
3 \\
3\end{array}$ & $\begin{array}{l}4 \\
4 \\
4\end{array}$ & $\begin{array}{l}5 \\
5 \\
5\end{array}$ \\
\hline 29. Comunidade & $\begin{array}{l}\text { A } \\
\text { B } \\
\text { C }\end{array}$ & $\begin{array}{l}1 \\
1 \\
1\end{array}$ & $\begin{array}{l}2 \\
2 \\
2\end{array}$ & $\begin{array}{l}3 \\
3 \\
3\end{array}$ & $\begin{array}{l}4 \\
4 \\
4\end{array}$ & $\begin{array}{l}5 \\
5 \\
5\end{array}$ \\
\hline 30. Seleção de Pessoal & $\begin{array}{l}\text { A } \\
\text { B } \\
\text { C }\end{array}$ & $\begin{array}{l}1 \\
1 \\
1 \\
\end{array}$ & $\begin{array}{l}2 \\
2 \\
2 \\
\end{array}$ & $\begin{array}{l}3 \\
3 \\
3\end{array}$ & $\begin{array}{l}4 \\
4 \\
4 \\
\end{array}$ & $\begin{array}{l}5 \\
5 \\
5 \\
\end{array}$ \\
\hline 31. Treinamento & $\begin{array}{l}\text { A } \\
\text { B } \\
\text { C }\end{array}$ & $\begin{array}{l}1 \\
1 \\
1 \\
\end{array}$ & $\begin{array}{l}2 \\
2 \\
2 \\
\end{array}$ & $\begin{array}{l}3 \\
3 \\
3 \\
\end{array}$ & $\begin{array}{l}4 \\
4 \\
4 \\
\end{array}$ & $\begin{array}{l}5 \\
5 \\
5 \\
\end{array}$ \\
\hline 32. Dirigir Grupos & $\begin{array}{l}\text { A } \\
\text { B } \\
\text { C }\end{array}$ & $\begin{array}{l}1 \\
1 \\
1\end{array}$ & $\begin{array}{l}2 \\
2 \\
2 \\
\end{array}$ & $\begin{array}{l}3 \\
3 \\
3 \\
\end{array}$ & $\begin{array}{l}4 \\
4 \\
4 \\
\end{array}$ & $\begin{array}{l}5 \\
5 \\
5\end{array}$ \\
\hline 33. Delegação de Poder & $\begin{array}{l}\text { A } \\
\text { B } \\
\text { C }\end{array}$ & $\begin{array}{l}1 \\
1 \\
1 \\
\end{array}$ & $\begin{array}{l}2 \\
2 \\
2 \\
\end{array}$ & $\begin{array}{l}3 \\
3 \\
3 \\
\end{array}$ & $\begin{array}{l}4 \\
4 \\
4 \\
\end{array}$ & $\begin{array}{l}5 \\
5 \\
5 \\
\end{array}$ \\
\hline $\begin{array}{l}\text { 34. Administração de } \\
\text { Mudança }\end{array}$ & $\begin{array}{l}\text { A } \\
\text { B } \\
\text { C }\end{array}$ & $\begin{array}{l}1 \\
1 \\
1 \\
\end{array}$ & $\begin{array}{l}2 \\
2 \\
2 \\
\end{array}$ & $\begin{array}{l}3 \\
3 \\
3 \\
\end{array}$ & $\begin{array}{l}4 \\
4 \\
4 \\
\end{array}$ & $\begin{array}{l}5 \\
5 \\
5 \\
\end{array}$ \\
\hline 35. Administração do Tempo & $\begin{array}{l}\mathrm{A} \\
\mathrm{B} \\
\mathrm{C}\end{array}$ & $\begin{array}{l}1 \\
1 \\
1\end{array}$ & $\begin{array}{l}2 \\
2 \\
2\end{array}$ & $\begin{array}{l}3 \\
3 \\
3\end{array}$ & $\begin{array}{l}4 \\
4 \\
4\end{array}$ & $\begin{array}{l}5 \\
5 \\
5\end{array}$ \\
\hline
\end{tabular}

